\title{
3. MAGNETIC FABRIC AS A STRAIN INDICATOR IN UNCONSOLIDATED SEDIMENTS OF THE CHILE TRIPLE JUNCTION AREA ${ }^{1}$
}

\author{
Hélène Collombat, ${ }^{2}$ Pierre Rochette, ${ }^{3}$ and Pierre Vialon ${ }^{2}$
}

\begin{abstract}
A combined study of anisotropy of magnetic susceptibility (AMS) and paleomagnetism of sediments from Leg 141 was achieved in order to better constrain directions of deformation in the Chile Triple Junction region. 157 paleomagnetic samples from the upper 20 to $80 \mathrm{mbsf}$ of the sediment sections of each of the five sites investigated during the leg were taken aboard the JOIDES Resolution and measured post-cruise. AMS directions were reoriented in geographic coordinates using the declination of natural remanent magnetization (NRM) cleaned with alternating field (AF). The results revealed that the magnetic fabric and the strain direction obtained from principal susceptibility axes at each site confirm the regional geodynamic context resulting from plate convergence. Below an upper part that generally does not exceed a few meters, the minimum susceptibility axis, $K 3$, is generally reoriented from a direction close to vertical, typical of a normal, primary sedimentary fabric, to a more horizontal and striking in a globally east-west azimuth direction. The direction of tightening and compression inferred from $K 3$ axes direction for each site is related to the location of the site with respect to the ridge and the trench and can be interpreted as a consequence of the overthrust. This study thus confirms the accuracy and the sensitivity of the AMS method as a strain indicator, even in weakly deformed sediments.
\end{abstract}

\section{INTRODUCTION}

The investigation of magnetic anisotropy in sediments allows us to define the ellipsoid of magnetic susceptibility, which is an image of the preferred orientation, or fabric, of the magnetic grains in the sediment. This ellipsoid is defined by the direction of its principal axes and their magnitude: $K 1 \geq K 2 \geq K 3$. Reported parameters are usually the mean susceptibility: $K m=(K 1+K 2+K 3) / 3$ and the anisotropy ratio: $P=K 1 / K 3, L=K 1 / K 2, F=K 2 / K 3$, the total, planar and linear anisotropy degree, respectively. From a description of the magnetic fabric in terms of shape and orientation of the susceptibility ellipsoid, inferences may be made concerning the deposition processes and subsequent deformation of the sediment (Hrouda, 1982; Borradaile, 1988; Jackson and Tauxe, 1991; Rochette et al., 1992).

Anisotropy of magnetic susceptibility (AMS) in sediments can be the result of lattice-preferred orientation of grains with a magnetocrystalline anisotropy (i.e., phyllosilicates, hematite), but in most cases, the main contribution to anisotropy is from the statistical shape alignment of nonspherical magnetite grains. When these magnetite grains are not in single domain state (i.e., size larger than $1 \mu \mathrm{m}$ ) their $K 1$ and $K 3$ axes correspond respectively to their long and short axis. This leads to a normal magnetic fabric (i.e., with correspondence between magnetic and structural foliation), as is the case for an AMS due to phyllosilicates. In an undeformed sediment, such grains tend to align their short axes perpendicular to the bedding plane, to produce a horizontal magnetic foliation (i.e., in the plane perpendicular to $K 3$ ), the so-called primary sedimentary fabric. A magnetic lineation (corresponding to $K 1$ direction) may indicate a bottom current during deposition. These primary depositional fabrics may be altered to varying degrees by subsequent perturbations or deformations and result in a secondary fabric in which the axes of minimum and maximum ( $K 3$ and $K 1)$ susceptibility correspond, respectively, to the directions of minimum and maximum principal strain axes. Applying this technique to sedimentary cores from drill holes requires an azimuthal orientation of the core, which can be completed using the direction of characteristic

\footnotetext{
'Lewis, S.D., Behrmann, J.H., Musgrave, R.J., and Cande, S.C. (Eds.), 1995. Proc. ODP, Sci. Results, 141: College Station, TX (Ocean Drilling Program).

${ }_{2}^{2}$ LGIT, IRIGM, BP 53-X, 3804 I Grenoble cedex, France.

${ }^{3}$ Laboratoire de Géochimie et Magnétisme des roches, Université d'Aix-Marseille III, Faculté st Jérôme, case 431, 13397 Marseille cedex 13. France.
}

natural remanence (ChRM) assumed to be on the average parallel to geographic north or south for sediments of the last m.y. In this paper, we present detailed results of AMS and paleomagnetic measurements from the five sites investigated during Ocean Drilling Program (ODP) Leg 141, in the region of the Chile Triple Junction, where the Chile spreading ridge is being subducted beneath the Peru-Chile Trench convergent margin. We propose a picture of deformation and strain development at each locality from the magnetic fabrics of the sediments and some tentative deductions regarding the regional paleostress field. Finally the effect of magnetic anisotropy on ChRM directions will be tested by correlating an eventual inclination shallowing of ChRM with the intensity of planar anisotropy.

\section{GEOLOGICAL SETTING AND PALEOMAGNETIC SAMPLING}

The Chile Triple Junction area, located near $46^{\circ} \mathrm{S}$ and $76^{\circ} \mathrm{W}$, is where collision between the actively spreading Chile Ridge and the Chile Trench subduction zone takes place (Herron et al., 1981; Cande and Leslie, 1986; Cande et al., 1987). Here, the Antarctic and the Nazca plates are both moving away from the Chile Ridge that separates them and being subducted eastward beneath the continental South America plate, along the Peru-Chile Trench. Regional plate tectonic reconstructions for the Chile Triple Junction constrained by marine magnetic anomaly studies (Pilger, 1978; Cande et al., 1982) show that the Chile Ridge first collided with the Chile Trench about 14 Ma near the latitude of Tierra del Fuego (Fig. 1A). As the ridge is subducted, the Chile Triple Junction migrates northward along the margin, until it reaches its present location, and the relative plate motions vector between the subducting and overriding plates changes: the subduction is slightly northeast and rapid north of the advancing Chile Triple Junction but slightly southeast and much slower following passage of the Chile Triple Junction.

Leg 141 occupied five sites off the coast of southern Chile, near $46^{\circ} \mathrm{S}$. Sites 859,860 , and 861 form a transect across the forearc about $40 \mathrm{~km}$ north of the triple junction (Figs. $1 \mathrm{~B}$ and 2), respectively 4,9 , and $16 \mathrm{~km}$ landward of the toe of the overriding forearc.

Site 862 is located near the crest of the prominent bathymetric Taitao Ridge, approximately $25 \mathrm{~km}$ south of the present location of the Chile Triple Junction. The Chile Trench is interrupted by the Taitao Ridge, and its axis is deflected from a north-south trend to a more 

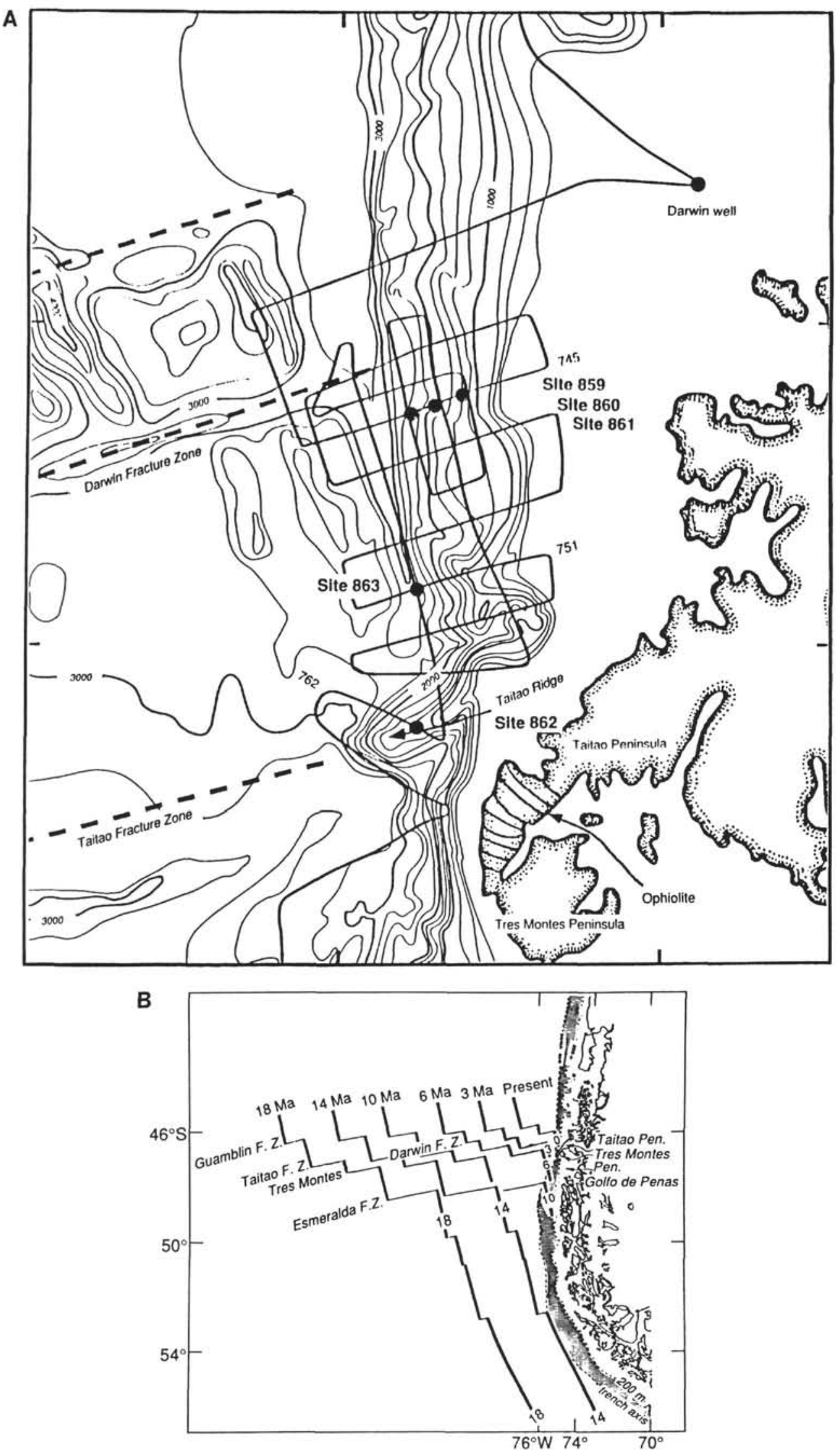

Figure 1. A. Bathymetric map of the Chile margin Triple Junction. Location of Sites 859, 860, 861, 862, and 863 (contour interval is $50 \mathrm{~m}$ ). From Behrmann, Lewis, Musgrave, et al., 1992. B. Sequential reconstruction of the Chile rise spreading ridge with respect to South America from $18 \mathrm{Ma}$ to the present. 

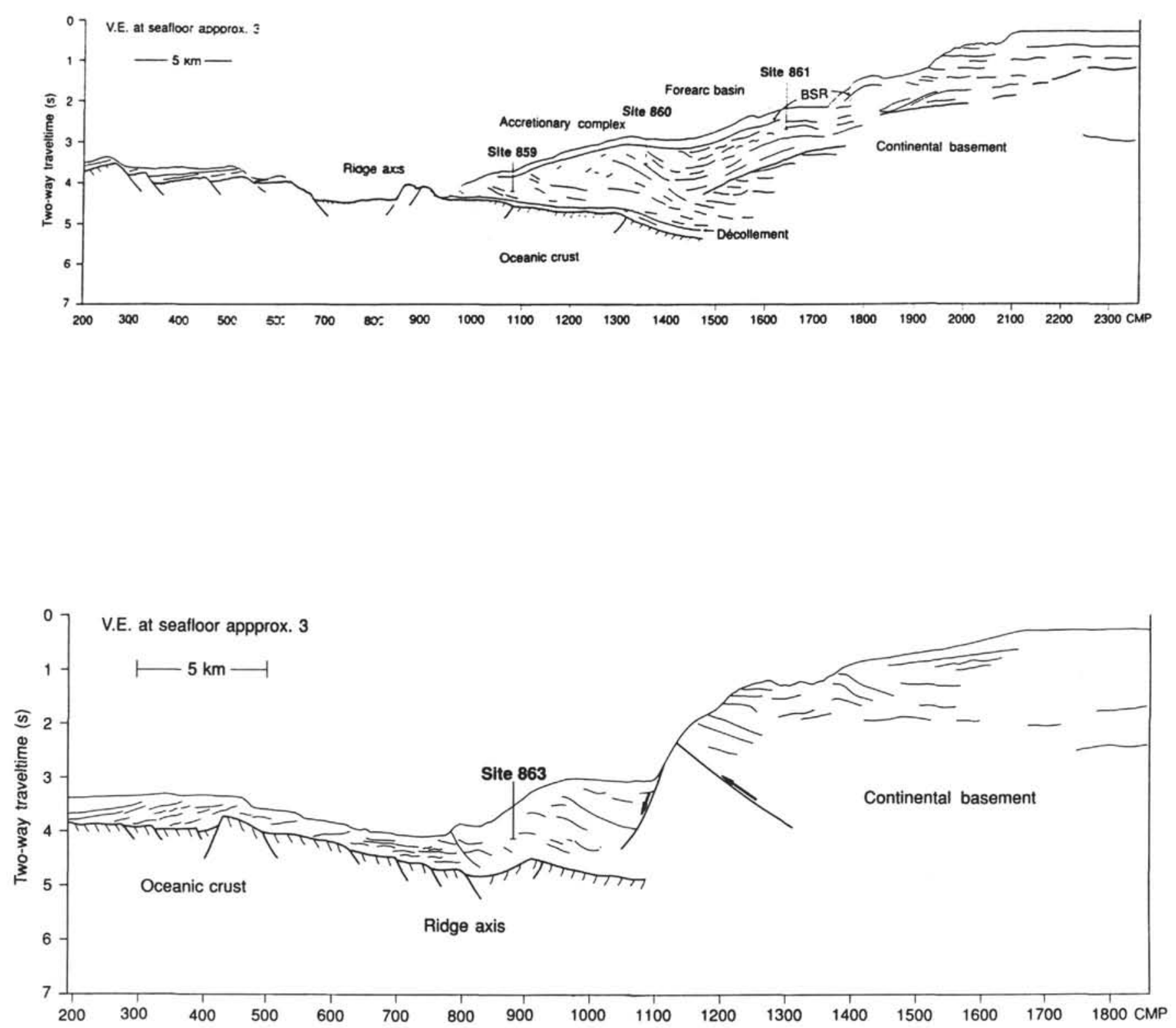

Figure 2. Interpretative cross-sections from seismic reflection Lines 745 (top) and 751 (bottom). Sites 859, 860, 861, and 863 are marked. From Behrmann, Lewis, Musgrave, et al., 1992.

southwesterly trend northwest of the Taitao Ridge (Fig. 1B). The proximity to the onshore Taitao Ophiolite, $20 \mathrm{~km}$ to the east (Taitao Peninsula) (Forsythe and Nelson, 1985), and the geophysical data suggest that the Taitao Ridge is of oceanic origin and may be in the process of accretion to the Chile Trench forearc. However, first results of the drilling at Site 862 does not allow us to determine whether the Taitao Ridge is presently attaching to the Antarctic Plate or to the South American Plate (Behrmann, Lewis, Musgrave, et al., 1992).

Site 863 is located in the toe region of the accretionary wedge overriding the axial zone of the Chile Ridge, just above the point where the ridge is being subducted.

Paleomagnetic samples were taken on board from the working half of each core taken with the advanced hydraulic piston core (APC). 157 discrete specimens were taken, approximately each 1.5 $\mathrm{m}$, in soft and semilithified sediment, using cubic plastic boxes with a volume of $8 \mathrm{~cm}^{3}$. The samples have been taken in sediment layers from silt to clay grain size ranges, the sand layers and the volcaniclastic sediments have not been sampled for the present study. Each cube has an arrow on the split core face pointing upcore, which allows an orientation in the core reference frame. The sampling was selective; zones too deformed where bedding was not preserved at all or soft zones with evidence of coring deformations were not sampled. As the Multishot tensor tool data for orientation of the APC cores was not always available, reorientation in the geographic reference frame of anisotropy of magnetic susceptibility directions was achieved by rotating the core around a vertical axis, from the declination of characteristic natural remanent magnetization (NRM) (oriented declination of principal susceptibility axis $\mathrm{K}_{\mathrm{i}}=$ Decl $\mathrm{K}_{\mathrm{i}}-$ Decl NRM).

\section{LABORATORY PROCEDURE \\ NRM Demagnetization}

Magnetic remanence measurements were made onshore using a Molspin magnetometer on the 157 discrete samples. Magnetic cleaning was performed using the Alternating field (AF) demagnetizer. Detailed progressive AF demagnetization at increments of 2.5 to 10 $\mathrm{mT}$, up to $70 \mathrm{mT}$ were performed for discrete specimens and analyzed using "Zijderveld" diagrams. We can see from these plots that a vis- 
cous remanent magnetization (VRM) is removed below $15 \mathrm{mT}$, and that the samples show stable direction of NRM after the 10 to $15 \mathrm{mT}$ cleaning (Fig. 3). At the maximum field of $70 \mathrm{mT}$, between $85 \%$ and $98 \%$ of the initial NRM was removed. We then partially AF demagnetized all samples at $15 \mathrm{mT}$ in order to work on stable characteristic remanence (ChRM).

\section{Anisotropy of Magnetic Susceptibility (AMS)}

The low field susceptibility and its anisotropy were measured onshore for all samples with a KLY-2 Kappabridge. At low field, the susceptibility is a second-order tensor represented by an ellipsoid with the three principal axes: $K 1 \geq K 2 \geq K 3$. The distribution of maximum and minimum susceptibility axes direction of all individual samples from one site will be represented by equal-area lower hemisphere projection of individual direction of $K 1$ and $K 3$. The parameters used to describe the measured ellipsoid will be the mean susceptibility $K m$, the anisotropy degree $P$, and the lineation and foliation parameters, $L$ and $F$.

\section{Anisotropy of Anhysteretic Remanence}

The anisotropy of anhysteretic magnetization (ARM) was acquired in an alternating field of $90 \mathrm{mT}$ in the presence of a $1 \mathrm{mT}$ steady field. Measurements were made after a $5 \mathrm{~min}$ delay to reduce the impact of any short-period viscosity. ARM was given and measured in four directions: up, down, and along the two perpendicular horizontal edges of our cubic samples. We define the ARM anisotropy ratio $(\mathrm{Ha})$ as the ratio of mean ARM induced in the horizontal plane to mean ARM induced in the vertical direction. The measurement procedure enabled us to estimate the repeatability of the measurements in the vertical direction and to average the anisotropy within the bedding plane. The expression of our ratio is:

$$
\mathrm{H}_{\mathrm{a}}=\frac{\mathrm{ARM}_{\mathrm{NS}}+\mathrm{ARM}_{\mathrm{EW}}}{2 \mathrm{ARM}_{\mathrm{V}}}
$$

How does this parameter compare to the more usual $\mathrm{Pa}$ and $\mathrm{Fa}$ parameters derived from the principal axes of the ARM ellipsoid?

If we assume that the vertical axis corresponds to the minimum axis of magnetic anisotropy $\left(\mathrm{ARM}_{3}=\mathrm{ARM}_{\mathrm{v}}\right)$ and that $\mathrm{ARM}_{\mathrm{NS}}+$ $\mathrm{ARM}_{\mathrm{EW}}$ is a good estimate of $\mathrm{ARM}_{1}+\mathrm{ARM}_{2}$ (see Collombat et al., 1993, for justification of these approximations), the expression of our ratio as a function of the principal anisotropy parameters becomes:

$$
\mathrm{H}_{\mathrm{a}} \approx \frac{\mathrm{ARM}_{1}+\mathrm{ARM}_{2}}{2 \mathrm{ARM}_{3}}=\frac{\mathrm{P}_{\mathrm{a}}+\mathrm{F}_{\mathrm{a}}}{2}
$$

This ration of anhysteretic remanence susceptibility will be used to reflect the fabric of the NRM-carrying particles.

\section{RESULTS}

\section{Paleomagnetic and Rock Magnetic Measurements}

Post-cruise rock magnetic analysis including Curie point determination, isothermal remanence (IRM) acquisition, IRM saturation coercivity, and hysteresis have been made on Leg 141 paleomagnetic samples by R.J. Musgrave (Musgrave et al., this volume). He obtained the following results concerning the magnetic carriers:

Curie point determination: The thermomagnetic Curie points determined using a Curie balance was around $580^{\circ} \mathrm{C}-590^{\circ} \mathrm{C}$ in the cooling run of most samples (Musgrave et al., this volume) and suggest that the principal phase present in the sediment is magnetite (Tarling, 1983).

IRM acquisition: All samples of APC cores were saturated by applied fields of about $0.2 \mathrm{~T}$ (Musgrave et al., this volume), suggesting the dominance of magnetite in the upper part of the sediment section.
Hysteresis: The coercivity defined by the hysteresis curve $\left(\mathrm{H}_{\mathrm{c}}\right)$ and the back-field coercivity of remanence $\left(\mathrm{H}_{\mathrm{cr}}\right)$ remained respectively in the ranges 6-16 and 38-43 (Table 1), with just one higher value (Sample 141-860B-2H-6, 71-73 cm), and this corresponds to a grain size higher than $5 \mathrm{~mm}$, referring to the results of Hartstra (1982) who correlated the hysteresis parameters to magnetite grain size. The normalization of $\mathrm{H}_{\mathrm{cr}}$ against $\mathrm{H}_{\mathrm{c}}$ gave an even more stable ratio that remains between 2.4 and 6 and corresponds to pseudo single domain (PSD) to multidomain (MD) particles (Day et al., 1977).

These results suggest that NRM is carried by detrital volcanogenic magnetite of medium grain size and of PSD to MD state. Unfortunately, the presented data are the only data available and the low number of samples does not allow us to detect an eventual magnetic grain size variation downcore that could influence the magnetic fabric.

Measurements of NRM: For Sites 859,860, and 861, directions of cleaned NRM show normal polarity and mean inclinations coherent with the expected geocentric axial dipole (GAD) field inclination at this location (i.e., derived from the hypothesis of a GAD field, $\mathrm{I}_{\mathrm{GAD}}=$ $-65^{\circ}$ at this location; Fig. 4 ; average inclination is computed using McFadden method). However, the upper part of these sites exhibits shallow inclinations, which may reflect an inclination error induced by the planar and horizontal fabric of the sediment (Jackson et al., 1991; Collombat et al., 1993). Site 862 exhibits more shallow inclinations. At Site 863, NRM inclinations are often quite steep although the studied interval shows steeply inclined bedding (Fig. 4), whereas the normal inclination of detrital remanent magnetization (DRM) for horizontal bedding should be $-65^{\circ}$ at this location. These high values of NRM inclination, combined with the fact that steep bedding is observed, could reflect an overprint by chemical remanent magnetization (Behrmann, Lewis, Musgrave, et al., 1992, p. 368).

\section{Anisotropy of Magnetic Susceptibility (AMS)}

Stereograms of AMS principal directions for each site are given in Figures 5B, 7B, 9, 11B and 13B. Bulk susceptibility $(\mathrm{Km})$ varies from very low values $\left(10^{-4} \mathrm{SI}\right)$ up to $6 \times 10^{-3} \mathrm{SI}$ (Figs. $6 \mathrm{C}, 8 \mathrm{C}, 10 \mathrm{C}, 12 \mathrm{C}$, 14C). However, these values are weak compared to the peak of susceptibility observed in volcanic sand layers containing high percentages of magnetic minerals, which exhibit $\mathrm{Km}$ of up to $10 \times 10^{-3}$ SI (Behrmann, Lewis, Musgrave, et al., 1992). The sand layers were not sampled for the present study. Given these values of $K m$ and the results of the above chapter, the mineralogical origin of AMS can be either linked to paramagnetic clays when $\mathrm{Km} \leq 3 \times 10^{-4}$ (Rochette, 1987 ) or to titanomagnetite grains for larger $K m$ values. Both cases lead to a normal magnetic fabric (i.e., coincident magnetic and strain axes; Rochette et al., 1992) except if titanomagnetite are in single domain state, which is not the case according to the hysteresis measurements performed by Musgrave et al. (this volume).

Principal directions of anisotropy and the evolution of anisotropy parameters with depth are analyzed for each site in order to establish the structural significance of the magnetic fabric. Declination of susceptibility directions in geographic coordinate are obtained by subtracting the ChRM declination in sample coordinates. This is based on the assumption that, on average, ChRM is parallel to geographic north.

\section{Site 859}

\section{Analysis of Anisotropy Directions}

Figure $5 \mathrm{~A}$ shows the variation of the direction of the minimum susceptibility axis $(K 3)$ at Site 859 . The data allow us to separate the sequence into two parts that show distinct and well-defined fabric (Fig. 5B):

1. The upper part, between 0 and $1020 \mathrm{~cm}$ below seafloor ( $\mathrm{cmbsf}$ ), exhibits $K 3$ inclination values well clustered about the vertical direc- 

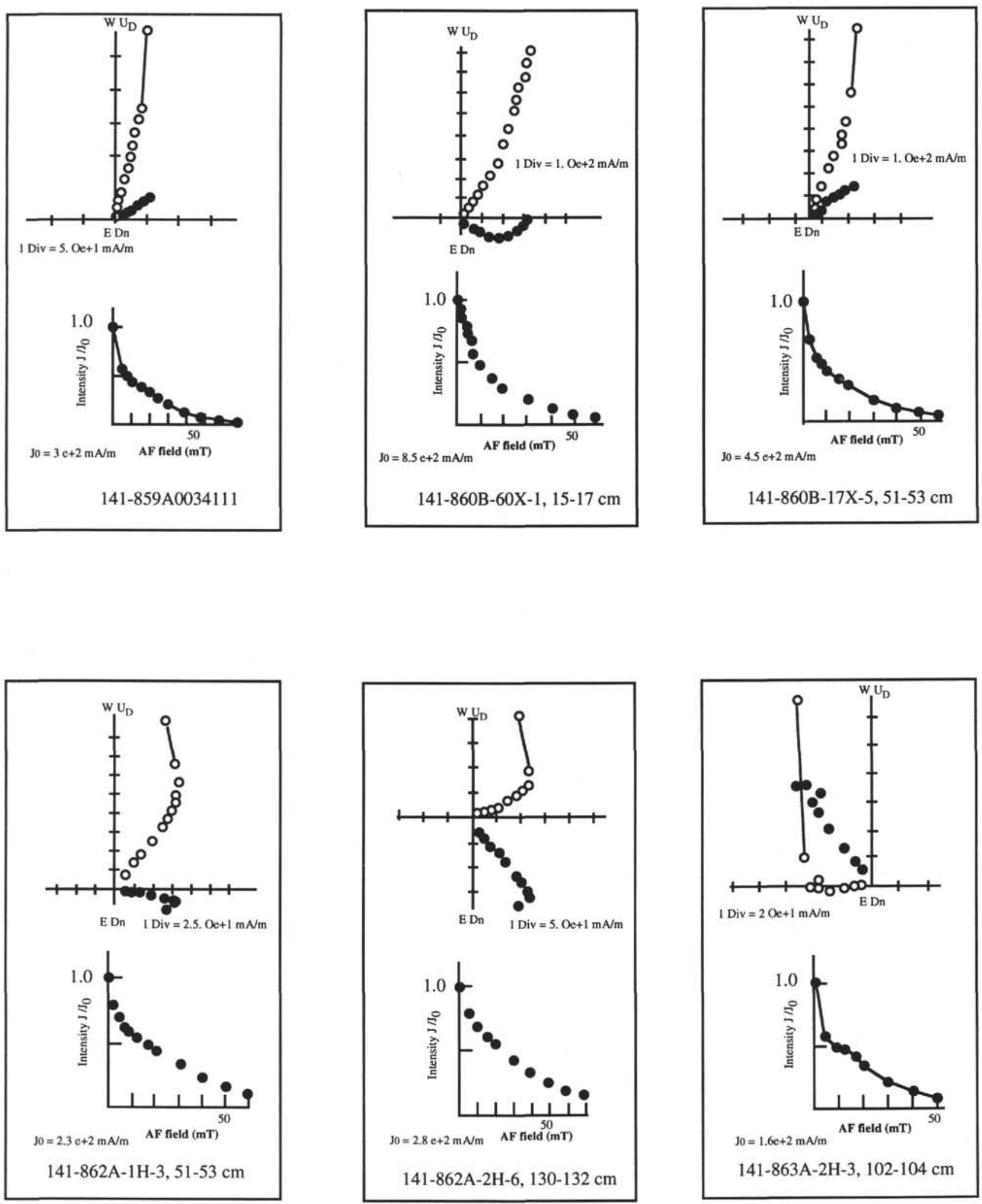

Figure 3. Zijderveld plots from AF demagnetizations for some samples from Sites $859,860,862$, and 863 . The VRM component is completely removed after $15 \mathrm{mT}$.

tion whereas maximum susceptibility axis $(K 1)$ are scattered in the horizontal plane. These directions suggest the presence of a primary planar depositional fabric. The bulk susceptibility is weak, at about $1.5 \times 10^{-3} \mathrm{SI}$ (Fig. 6). This part is characterized by high porosity and a steep downward gradient of decreasing values of this parameter (e.g., "Physical Properties" section of "Site 859" in Behrmann, Lewis,
Musgrave, et al., 1992). This part contains complex (and overturned) folded strata that have not been sampled (Behrmann, Lewis, Musgrave, et al., 1992). In this unit, the sediment is composed of clayey silt with siliceous $(\sim 13 \%)$ and calcareous $(\sim 7 \%)$ microfossils and minor amounts of glassy volcanic fragments, amphibole, opaque minerals, and biotite (Behrmann, Lewis, Musgrave, et al., 1992). 


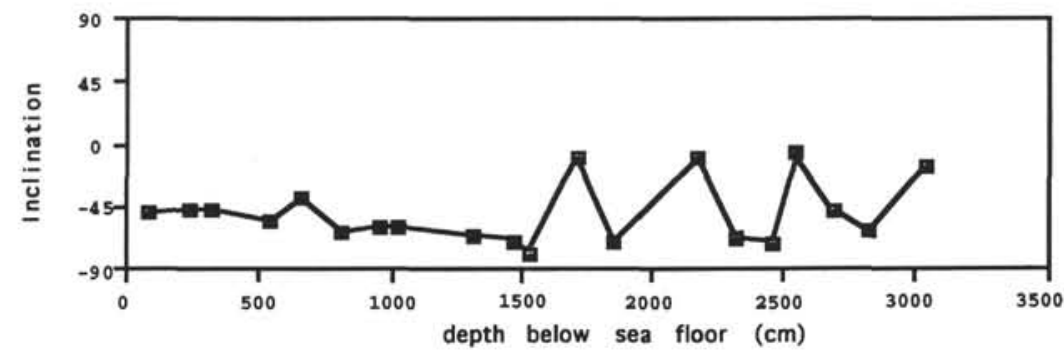

\section{SITE $\quad 859$}

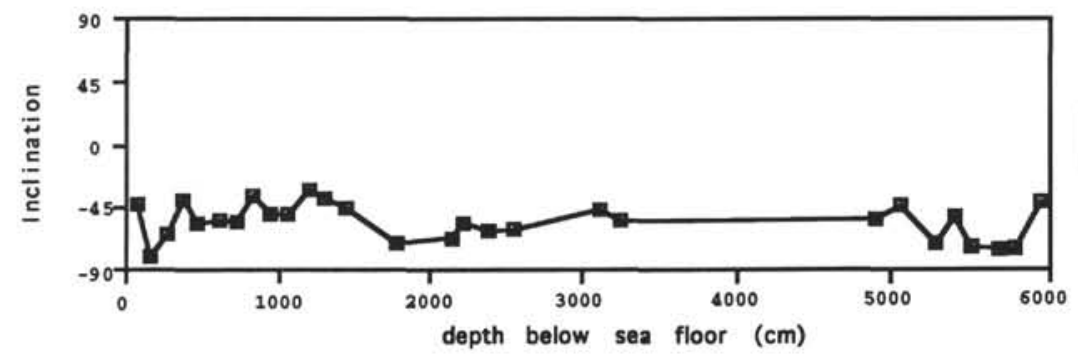

SITE 860

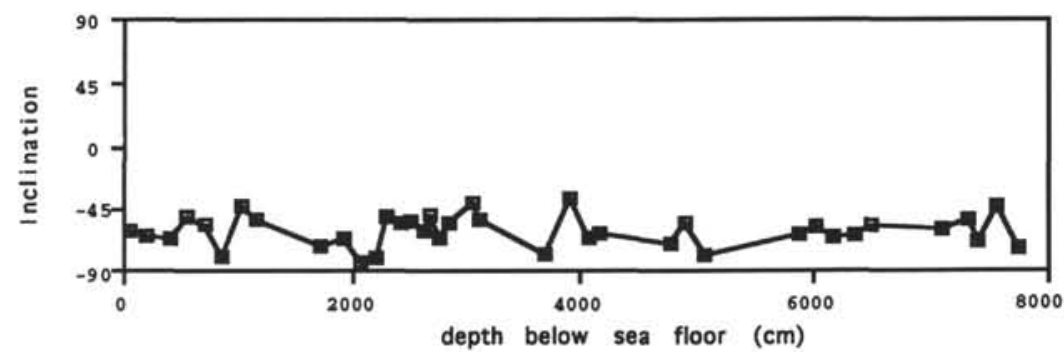

SITE $\quad 861$

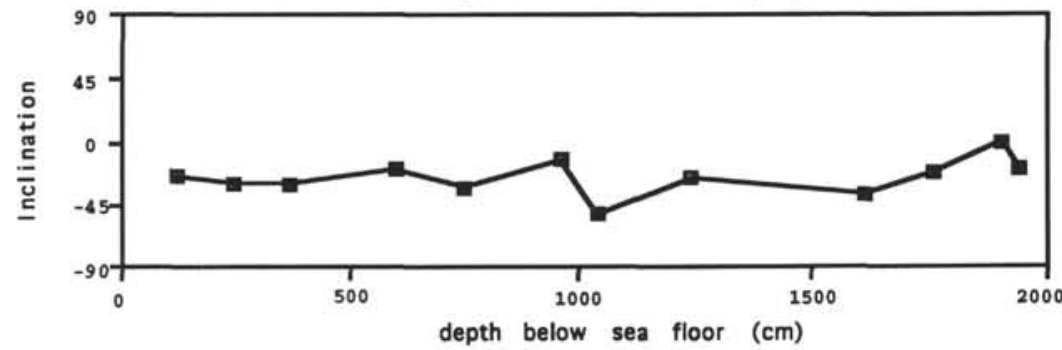

SITE $\quad 862$

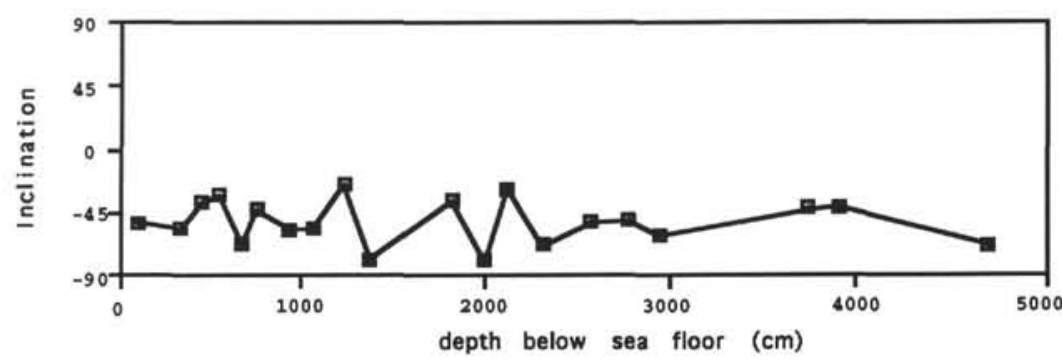

SITE 863

\begin{tabular}{|c|c|c|c|c|c|}
\hline SITE & 859 & 860 & 861 & 862 & 863 \\
\hline $\mathbf{N}$ & 20 & 28 & 37 & 12 & 20 \\
\hline $\mathbf{I}_{\text {average }}$ & -50.1 & -57.7 & -61.8 & -22.8 & -54.3 \\
\hline$\alpha_{\mathbf{9 5}}$ & 15 & 6.4 & 4.6 & 15.8 & 9.3 \\
\hline
\end{tabular}

Figure 4. $\log$ and average values of NRM inclination for each site $\left(\mathrm{N}=\right.$ number of samples; $\mathrm{I}_{\text {average }}=$ calculated average inclination ; $\alpha_{95}=$ half angle of a cone centered on $\mathrm{I}_{\text {average }}$ and containing the true average inclination with a probability of $95 \%$ ). 

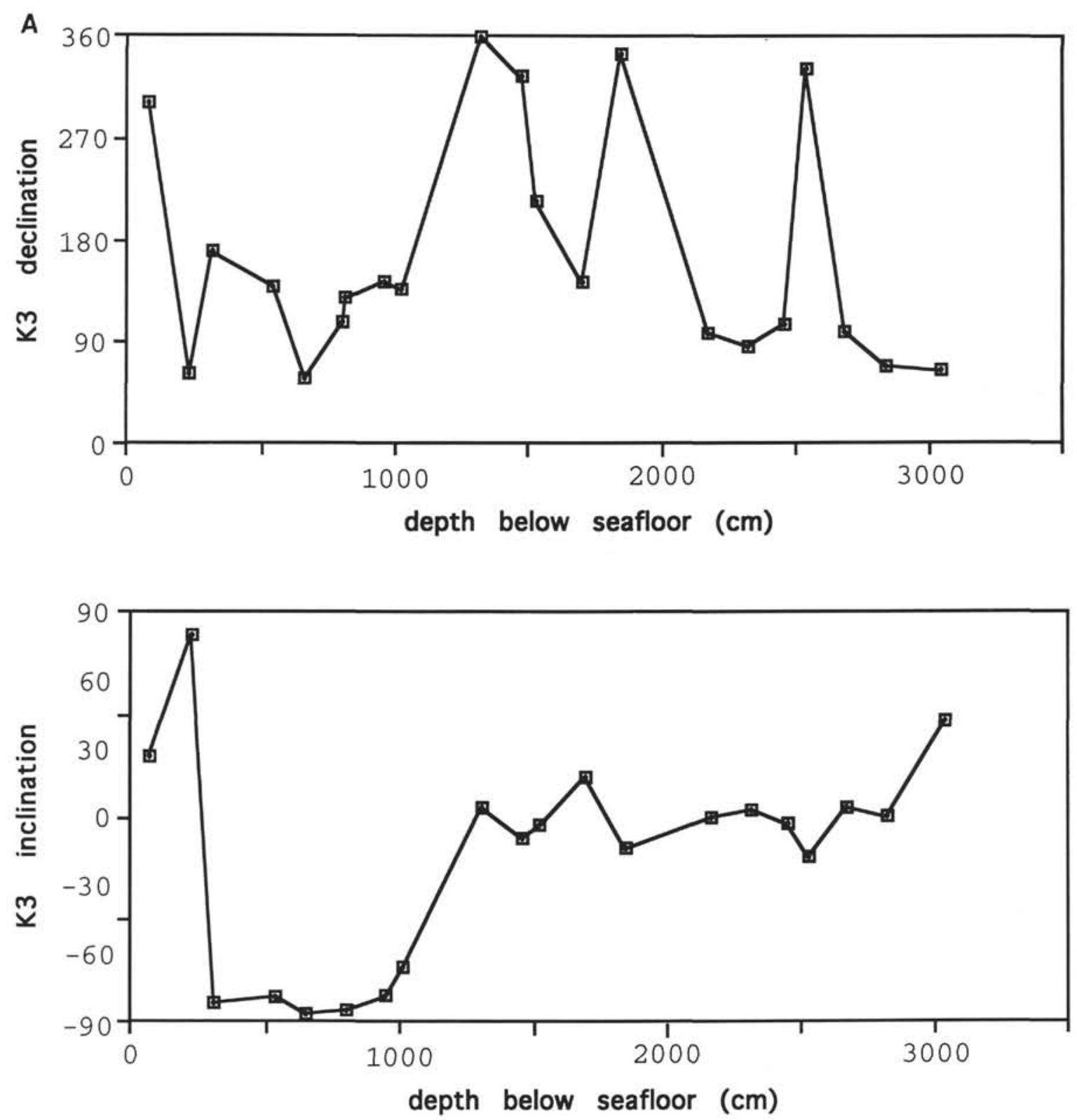

B

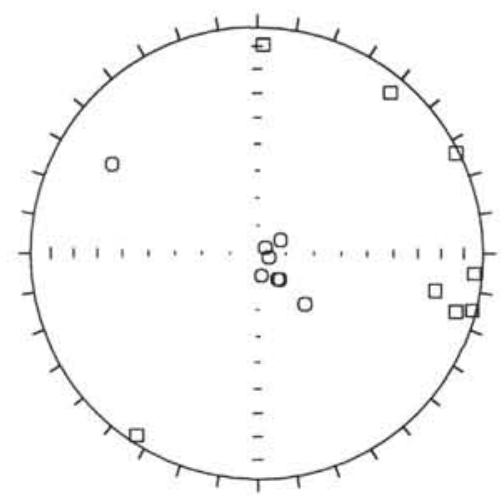

ams 859

top

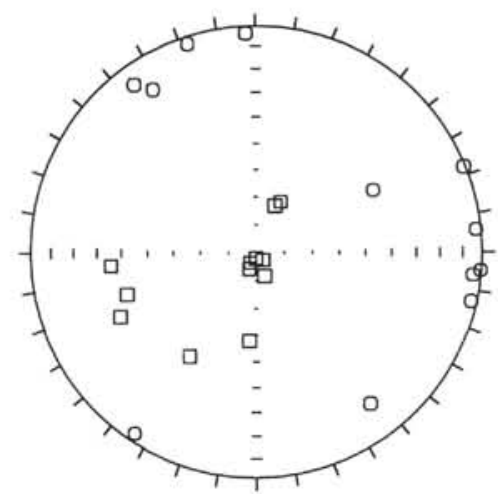

ams 859 bottom

Figure 5. A. Variation of $K 3$ declination and inclination with depth at Site 859. B. Stereograms of AMS principal directions at Site 859 for the top ( $0-1026 \mathrm{cmbsf})$ and the bottom of the section (1320-3047 cmbsf). Lower hemisphere projection in geographic coordinates (assuming ChRM along north) showing individual $K 3$ (circles) and $K 1$ (squares) specimen directions together with tensorial averaged directions and their ellipse of confidence (Jelinek, 1978). 
A

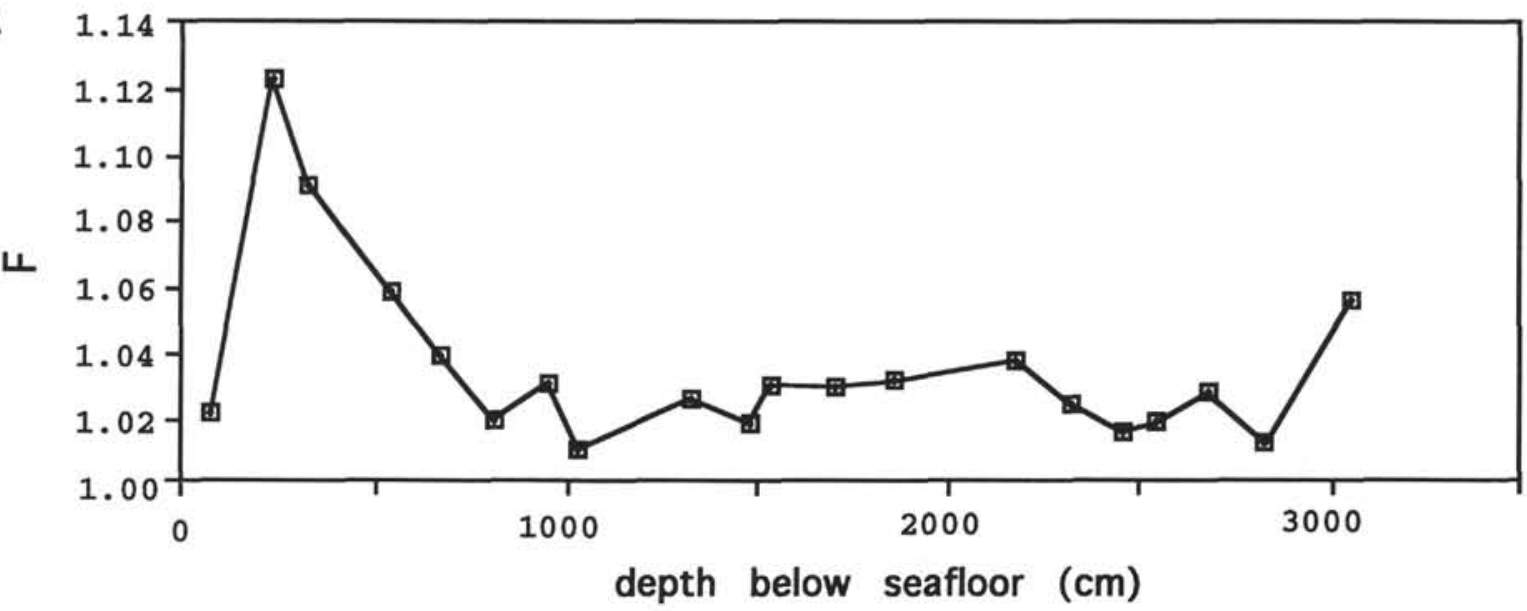

B
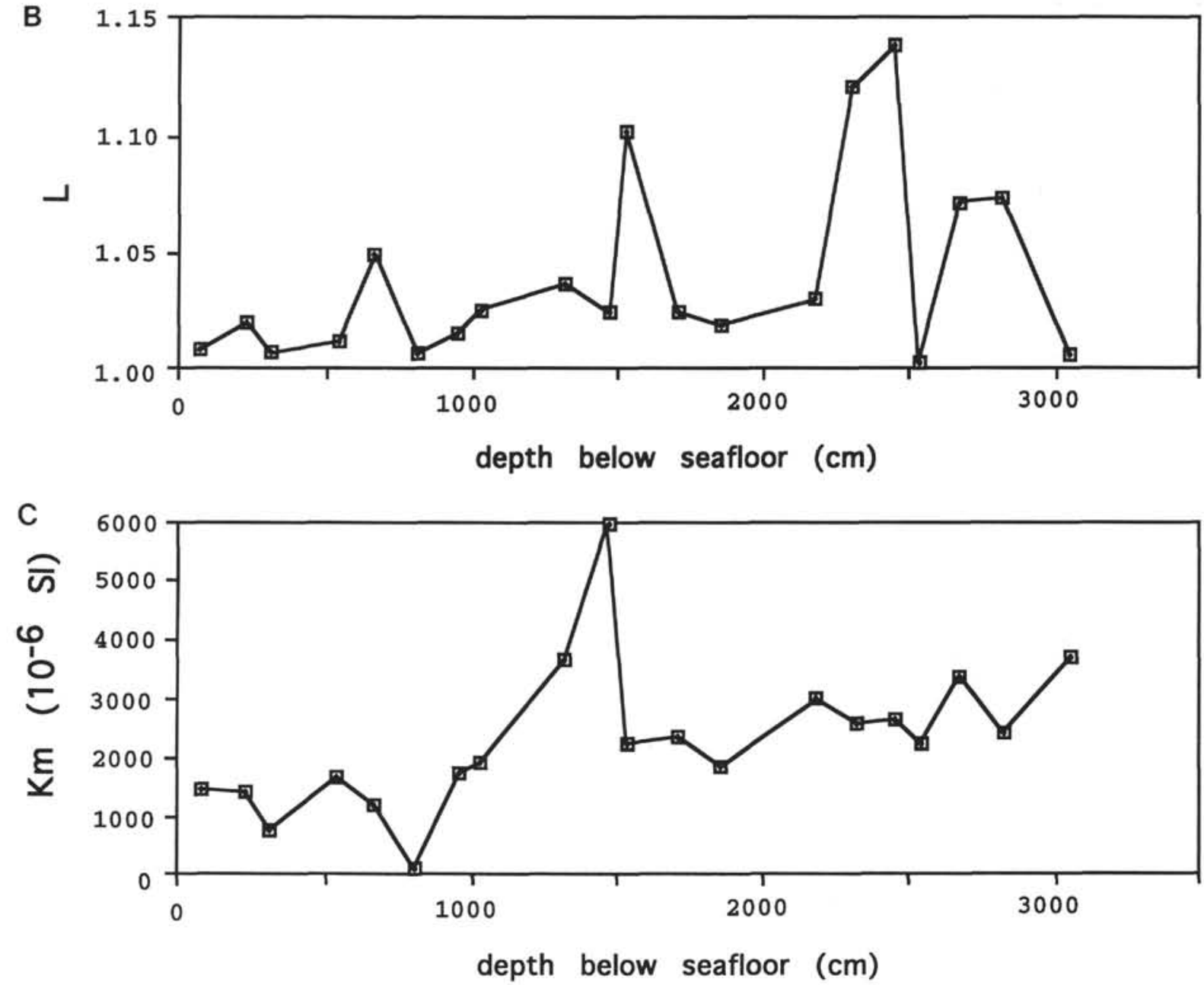

Figure 6. Evolution with depth at Site 859. A. Magnetic foliation parameter, $F$. B. Magnetic lineation parameter, $L$. C. Bulk susceptibility.

2. The lower part, between 1020 and $3050 \mathrm{cmbsf}$, corresponds to clay-sized and silt-sized terrigenous and volcaniclastic materials (silt is composed of quartz, feldspars, and lesser amounts of mica, amphibole, epidote, zircon, pyroxene, opaque minerals, and siliceous and calcareous microfossils) (Behrmann, Lewis, Musgrave, et al., 1992). This part is marked by an increase of bulk susceptibility (from an average of $1.5 \times 10^{-3} \mathrm{SI}$ to an average of about $3 \times 10^{-3} \mathrm{SI}$; Fig. 6), which could be the result of the diagenetic alteration of the magnetic mineralogy.
This lower part also exhibits a scattering of the $K 3$ axis in an approximately horizontal plane, mostly between $320^{\circ}$ and $220^{\circ}$ azimuths whereas the $K 1$ axis are distributed around the vertical direction, mostly in the southwest quadrant. Although the $K 3$ axis azimuths are scattered, we can notice a slight overall clustering tendency in an approximately east-west azimuth for $K 3$ declinations in the lowermost $1000 \mathrm{~cm}$. The bedding in these cores is mostly gently inclined, but the samples have been taken in nondisturbed layers, where the bedding was close to horizontal. 
We can interpret this nonsedimentary fabric below $1300 \mathrm{cmbsf}$ as caused by a global horizontal and east-west maximum shortening at the site scale, perpendicular to the ridge axis. The grouping of $K 1$ about the vertical could reflect a vertical stretching or flowing (parallel to $K 1$ ).

The alternative explanation of our results is the phenomenon of inverse fabric caused by the presence of paramagnetic iron-bearing calcite, or single domain magnetite. In such minerals, $K 3$ appears parallel to the lineation and $K 1$ perpendicular to the foliation plane (Rochette et al., 1992). This explanation is unlikely because of the presence of PSD to MD magnetite in the second part of the studied section, at $15.72 \mathrm{mbsf}$ (Fig. 3B; Musgrave et al., this volume) and the occurrence of a normal, primary fabric in the upper unit, which shares the same mineralogy with the lower unit.

\section{Intensity and Shape of the Magnetic Ellipsoid}

The total anisotropy $(P)$ is about 1.07 for the mean value and varies from very low values up to 1.15 . The shape of the susceptibility ellipsoid evolves from slightly oblate field (dominated by foliation) at the top of the core to the slightly prolate field (dominated by lineation) below $500 \mathrm{cmbsf}$ (Figs. 6A and 6B). We can interpret these results by the presence of an upper section exhibiting a primary sedimentary fabric. In the deepest part of the sequence, some samples exhibit relatively high values of lineation (up to 1.14) characteristic of a deformation fabric. This deformation can be related to the flowing mechanism with vertical stretching suggested by the vertical direction of $K 1$ of the corresponding samples.

The results at Site 859 can be accounted for by the following hypothesis:

Normal polarity of the NRM data suggests that sediments were deposited during the Brunhes Chron. The pattern of repeated short normal and reversed polarity intervals between 1700 and $3000 \mathrm{cmbsf}$ may represent transitional field behavior near the Matuyama/Brunhes reversal, which occurred at $0.7 \mathrm{Ma}$. However, the actual position of this boundary may lie deeper, anywhere between 30 and $6800 \mathrm{cmbsf}$, where upper Pliocene foraminifers have been identified.

The upper section (0-1000 cmbsf) exhibits a primary sedimentary fabric. Below the first $1000 \mathrm{~cm}$, the magnetic fabric is essentially the result of deformation with almost no residual depositional fabric. Despite slightly scattered directions, the dominant effect is the spreading of the $K 3$ axes in the horizontal plane (with a slight grouping in an approximately east-west azimuth) and the grouping of $K 1$ axis near the vertical. Together with the relatively high values of lineations, this can be interpreted as an upward vertical flowing or stretching of the sediment resulting from the deformation.

\section{Site 860}

\section{Analysis of Anisotropy Directions}

The $6000-\mathrm{cm}$ sediment sequence sampled at Site 860 can be divided in three parts showing distinct magnetic fabric (Figs. 7 and 8). These three parts do not exhibit obvious changes in sediment porosity (Behrmann, Lewis, Musgrave, et al., 1992) that could be related to the change of the magnetic fabric.

An upper disorganized section exhibits quite shallow $K 3$ inclinations and varying $K 3$ declinations in the first $500 \mathrm{cmbsf}$ (probably owing to bioturbation and possibly increased by sampling deformations). Bulk susceptibility increases from $1 \times 10^{-3} \mathrm{SI}$ to $3 \times 10^{-3} \mathrm{SI}$.

In the second domain (500-1800 cmbsf), the $K 3$ directions lie close to the vertical $\left(\mathrm{I} K 3=73^{\circ}\right)$ in the northwest quadrant, whereas $K 1$ axes are scattered in a subhorizontal bedding plane. These data can be interpreted as a planar and weakly tilted sedimentary fabric, which is confirmed by the low NRM inclination values compared with the $-65^{\circ}$ inclination of the GAD ( $\mathrm{I}_{\mathrm{NRM}}$ is about $48^{\circ}$ in average in this zone). The bedding dip slightly to the east-southeast (Behrmann, Lewis, Musgrave, et al., 1992), which is consistent with the interpretative cross section (Fig. 2A).
Table 1. Coercivity from hysteresis $\left(\mathrm{H}_{\mathrm{c}}\right)$, coercivity of saturation remanence $\left(H_{c}\right)$, and the $H_{c r} / H_{c}$ ratio for sediment samples of APC cores from Leg 141 (after Musgrave et al., this volume).

\begin{tabular}{lrrrr}
\hline $\begin{array}{c}\text { Core, section, } \\
\text { interval }(\mathrm{cm})\end{array}$ & $\begin{array}{c}\text { Depth } \\
\text { (mbsf) }\end{array}$ & $\begin{array}{c}\mathrm{H}_{\mathrm{c}} \\
(\mathrm{mT})\end{array}$ & $\begin{array}{c}\mathrm{H}_{\mathrm{sr}} \\
(\mathrm{mT})\end{array}$ & $\mathrm{H}_{\mathrm{cr}} / \mathrm{H}_{\mathrm{c}}$ \\
\hline $141-859 \mathrm{~A}-3 \mathrm{H}-4,52-54$ & 15.72 & 15.37 & 42.60 & 2.77 \\
$141-860 \mathrm{~B}-2 \mathrm{H}-6.71-73$ & 9.61 & 38.41 & 92.61 & 2.41 \\
$141-861 \mathrm{~A}-1 \mathrm{H}-3.54-56$ & 3.54 & 11.60 & 38.09 & 3.28 \\
$141-861 \mathrm{C}-5 \mathrm{H}-7.1113-115$ & 40.43 & 15.90 & 43.6 & 2.74 \\
$141-863 \mathrm{~A}-3 \mathrm{H}-4.63-65$ & 23.23 & 6.22 & 38.8 & 6.24 \\
\hline
\end{tabular}

The third part of the sequence ( $1800-5800 \mathrm{cmbsf})$, despite a lack of samples from 3200 to $4900 \mathrm{cmbsf}$ (which consists of massive, fineto medium-grained volcanic sand), exhibits a less well-defined fabric. The $K 1$ axes are displaced toward the vertical direction and the mean $K 3$ axis progressively shallows with depth in an approximately westnorthwest azimuth. The evolution of the fabric with depth can be related to tightening and compression linked to the collision or to gravity-induced deformation.

\section{Intensity and Shape of the Magnetic Ellipsoid}

The degree of anisotropy is generally small (mean $P=1.05$ ), suggesting only moderate deformation. The whole sequence is defined by a thin disorganized layer with varying foliation (1.01-1.06) followed by a $500-1800 \mathrm{cmbsf}$ zone exhibiting very low anisotropy ( $L=1.02, F=1.01$; Fig. 8). A very weak bulk susceptibility in this zone (about $240 \times 10^{-6}$ SI) combined with these low values of anisotropy can be linked to a change in lithology from the remainder of the sequence.

In the deepest part of the sequence $(1800-5800 \mathrm{cmbsf})$, the foliation remains in the range of a few percent $(F \leq 1.06)$ and the lineation increases from a few percent up to more than $12 \%(L>1.12)$, which suggests a strong stretching. The ellipsoid is prolate (with corresponding $K 1$ axes close to vertical) at the end of the drilled sequence and may have suffered vertical stretching. These high values of lineation and the tendency of corresponding $K 1$ axes to group about the vertical can be attributed the same deformation process of vertical flowing as at the bottom part at Site 859 (i.e., west-northwest-eastsoutheast shortening and vertical stretching of the sediment).

\section{Site 861}

\section{Analysis of Anisotropy Directions}

Figure 9 shows the direction of the principal axes of magnetic susceptibility and the variation of the $K 3$ direction with depth. Although the pattern of the principal axes of susceptibility is patchy, the $K 3$ axes are statistically grouped about vertical. However, three intervals near 20,40 , and 80 mbsf show a spreading to shallower inclinations, striking in a roughly $\mathrm{N} 120^{\circ}$ azimuth. The $K 1$ axes are scattered in an approximately horizontal plane, which can be related to a poorly defined foliation plane.

The global sediment structure at Site 861 is horizontal to gently inclined bedding. Despite its scattering, the pattern of the susceptibility principal axes is characteristic of a primary depositional fabric. Some deformed zones at 2000 and $3500-4000 \mathrm{cmbsf}$ exhibit high values of lineations and the horizontal $K 3$ axis striking in a $\mathrm{N}^{\circ} 0^{\circ}$ azimuth.

\section{Intensity and Shape of the Magnetic Ellipsoid}

Numerical values of $L$ and $F$ vary at Site 861 from very low intensity to more than 1.1 (Fig. 10). There is an overall tendency toward an oblate susceptibility ellipsoid corresponding to the typical primary sedimentary fabric zones, but some intervals (at about 2000 and $3600 \mathrm{cmbsf}$ ) exhibit high values of $L$ and a strongly prolate 

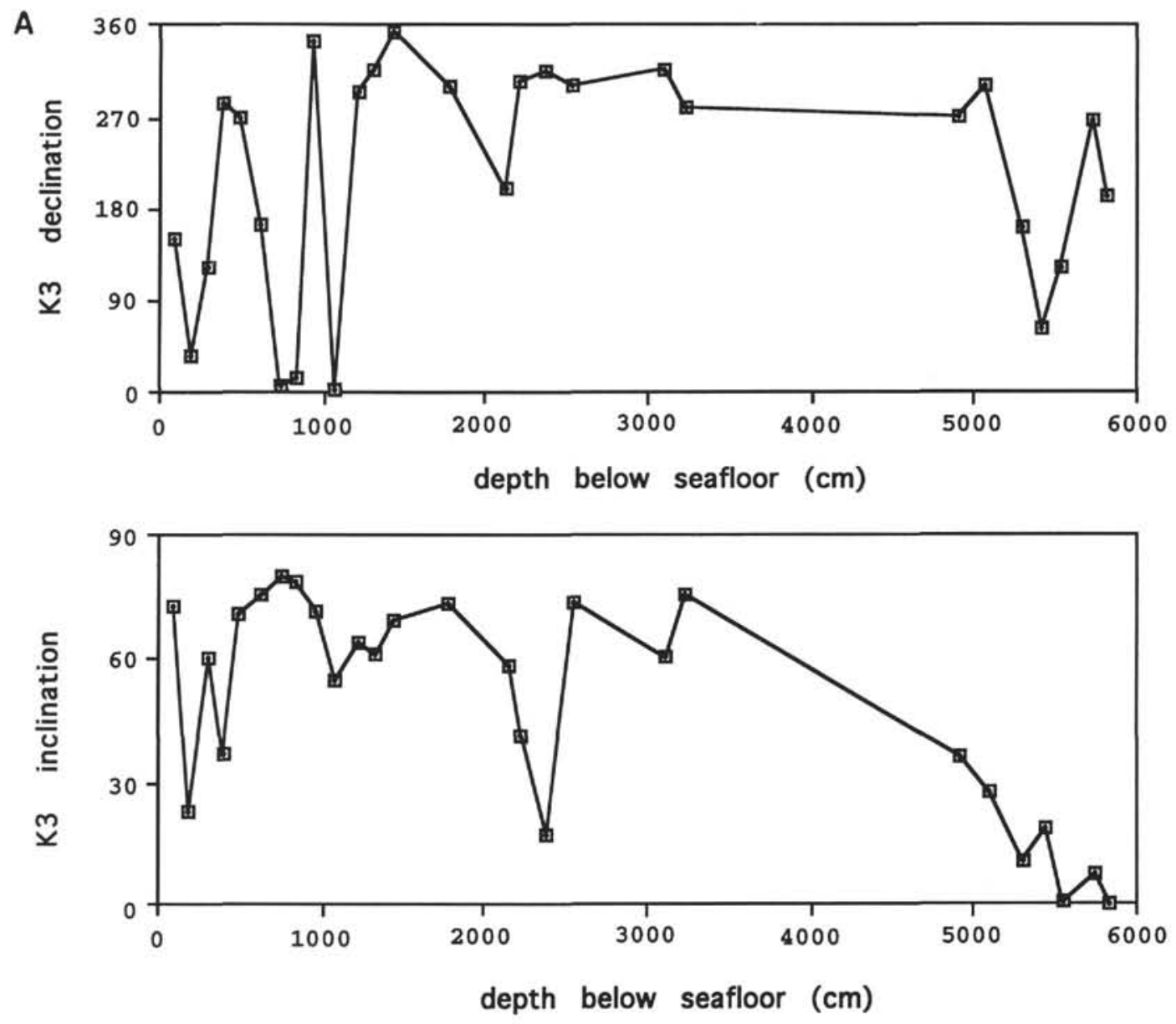

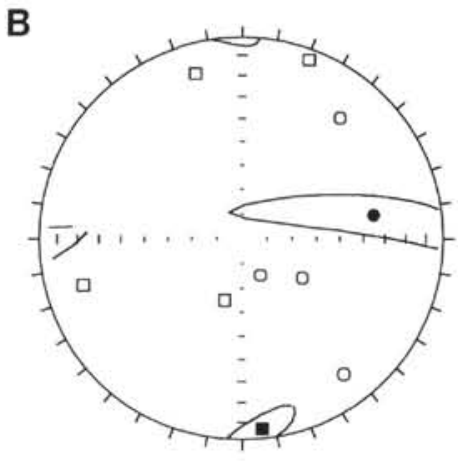

ams 860 top

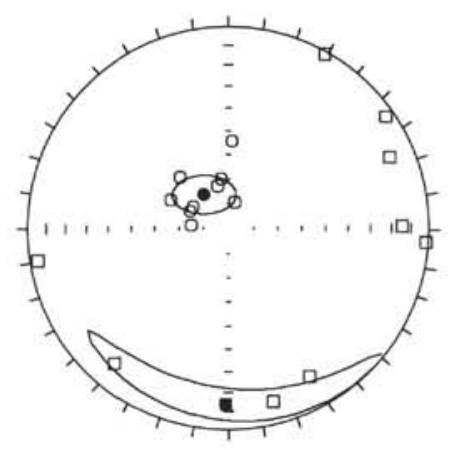

ams 860 middle

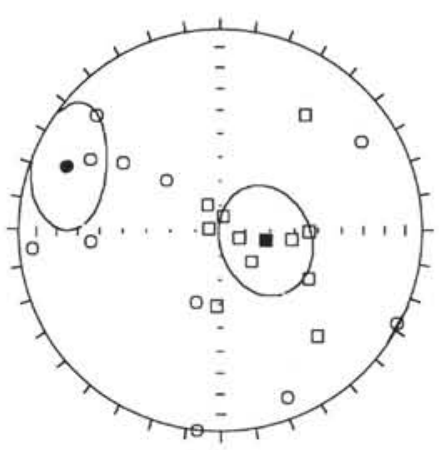

ams 860 bottom

Figure 7. A. Variation of $K 3$ declination and inclination with depth for Site 860 . B. Stereograms of AMS principal directions at Site 860 for the top (0-380 $\mathrm{cmbsf}$ ), middle ( $474-1775 \mathrm{cmbsf}$ ), and bottom parts of the section (2134-5814 cmbsf). Lower hemisphere projection in geographic coordinates (assuming ChRM along north) showing individual $K 3$ (circles) and $K 1$ (squares) specimen directions together with tensorial averaged directions and their ellipse of confidence (Jelinek, 1978).

susceptibility ellipsoid. These samples also show a shallow $K 3$ axis striking with a $\mathrm{N} 90^{\circ}$ to $\mathrm{N} 130^{\circ}$ azimuth. This can be interpreted as the presence of a weak deformation (east-west to northwest-southeast shortening) superimposed on the primary depositional fabric, or, more straightforwardly, by lithologic variation, especially for the low values of anisotropy parameters between 23 and 30 mbsf, which are probably linked with a lithologic change according to the very low bulk susceptibility at these depths.

Although this site shows less deformation than at Sites 859 and 860 , with a globally primary sedimentary fabric, the weakly deformed zones confirm the general tendency of a east-west to northwestsoutheast tightening, which could result from plate convergence.

\section{Site 862}

The lithology of the sediment sequence at this site is composed of consolidated marine claystone, silty claystone, sand, and sandstone. The structure is dominated by a set of steep normal faults, changes in the dip of bedding, and development of breccia in clay lithology. The sand and breccia layers were not sampled. 
A

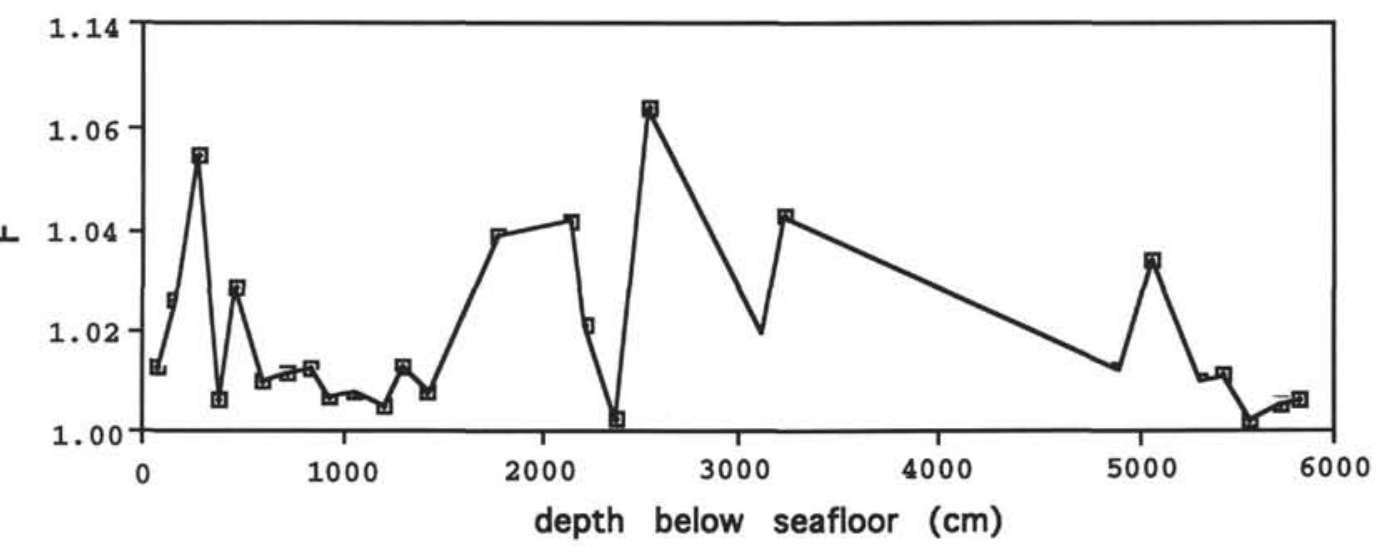

B
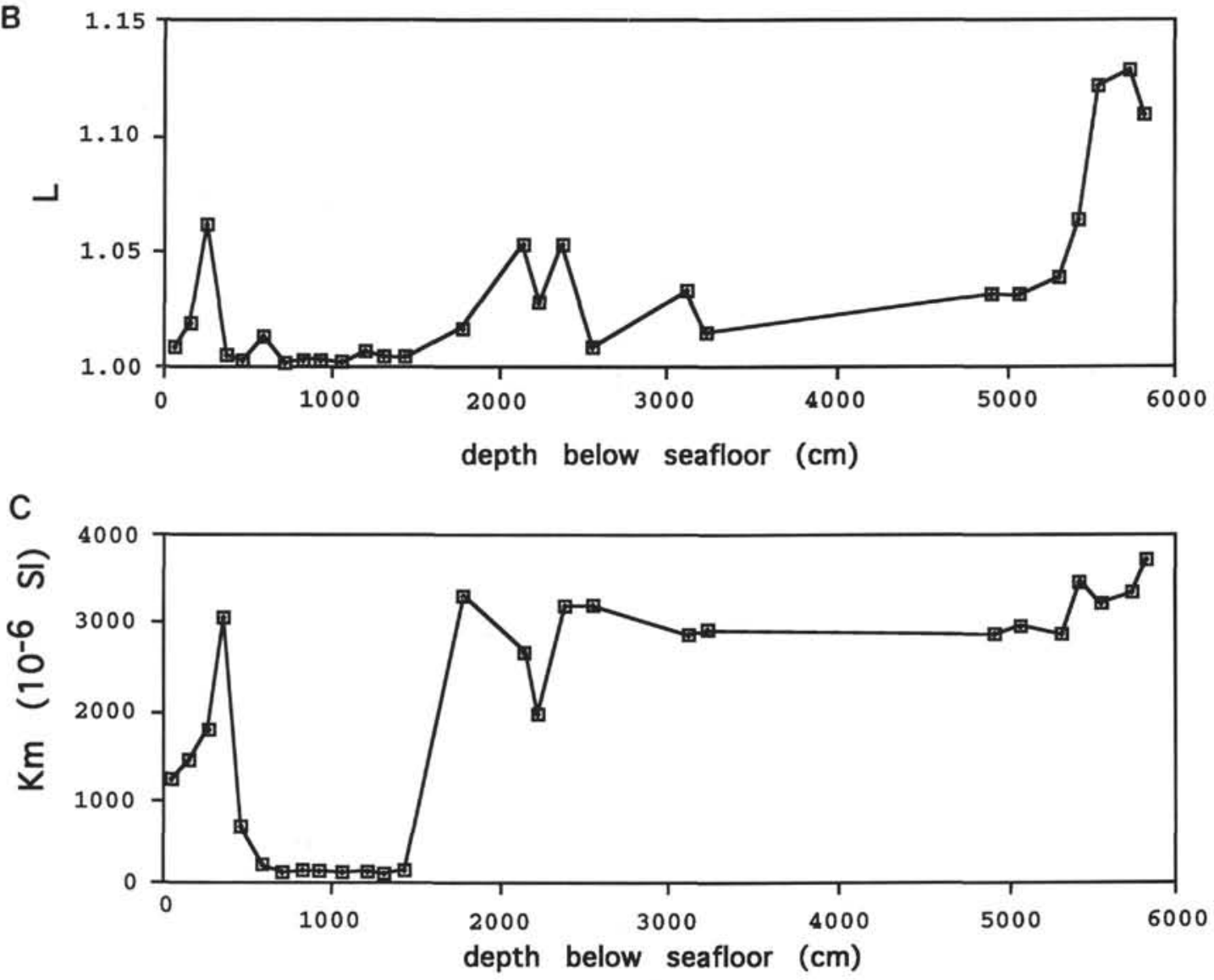

Figure 8. Evolution with depth at Site 860. A. Magnetic foliation parameter, F. B. Magnetic lineation parameter, $L$. C. Bulk susceptibility.

\section{Analysis of Anisotropy Directions}

Although the drilled sedimentary sequence extends only to 2300 cmbsf at Site 862, the direction of the principal axes of susceptibility shows a well-defined magnetic fabric (Figs. 4 and 11A). In the presentday geographic coordinates, the minimum susceptibility axes are very well clustered in an azimuth $\mathrm{N} 350^{\circ}$ with an inclination of about $60^{\circ}$. Maximum susceptibility axes $(K 1)$ are scattered in a plane perpendicular to the mean $K 3$.

\section{Intensity and Shape of the Magnetic Ellipsoid}

The high degree of anisotropy $(\mathrm{P}>1.1$ average) suggests that the fabric could be the result of deformation superimposed on the primary depositional fabric. However, the ellipsoid is strongly oblate with val- ues of $F$ more than one order of magnitude higher than the $L$ values (Fig. 12B). The anisotropy is predominantly planar and the fabric is close to horizontal so that it can also indicate a sedimentary fabric with a strong foliation, as resulting from a high sedimentation rate and compaction.

The bulk susceptibility varies widely from low values to more than $6 \times 10^{-3} \mathrm{SI}$ and gives evidence for changes in lithology.

Site 862 is located on a steep west-southwest-trending slope of the Taitao Ridge. This ridge may have been originated by a transform fault occurring along the Taitao Fracture Zone. The axis of the Chile Trench is deflected from its roughly north-south trend north of the Taitao Ridge, to a more southwesterly trend northwest of the Taitao Ridge. The deformation would most likely be caused by extension provided by the topographic slope in the near-surface sediments (as confirmed by the normal fault set that dominates the structure at this site). However, the AMS data at Site 862 (high degree of anisotropy 

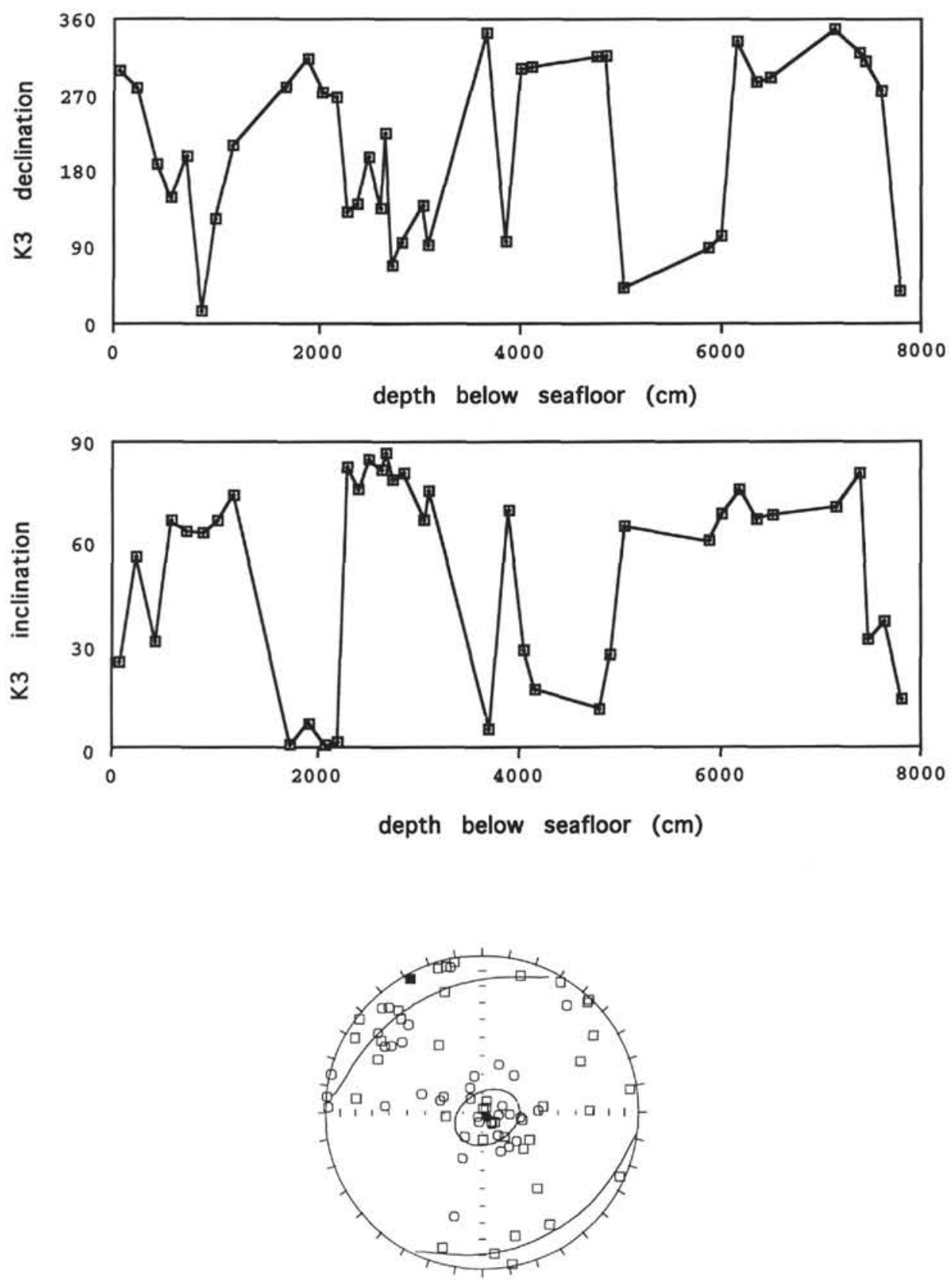

ams 861

Figure 9. Variation of $K 3$ declination and inclination with depth at Site 861 .

and grouping of $K 3$ in a north-northwest azimuth) suggest that the magnetic fabric could be the result of a north-northwest-southsoutheast and nonhorizontal maximal shortening, which may have resulted from the plate convergence and thrusting. The direction of the principal susceptibility axes could as well be interpreted as a sedimentary fabric, and the $60^{\circ}$ north-northwest inclination of the $K 3$ axes could be explained by the dipping of the bedding into the slope of the seafloor (which is approximately $30^{\circ}$ ).

\section{Site 863}

The data for Site 863 have not been corrected for the drift of the drill string from vertical. At this site, the Multishot data show drifts of about $5^{\circ}$ for sections between 2800 and $4000 \mathrm{cmbsf}$.

\section{Analysis of Anisotropy Directions}

The data allow us to separate the sampled section into two parts (Fig. 13), which do not show large changes in sediment porosity or magnetic susceptibility of the sediment (e.g., "Physical Properties" and "Paleomagnetism" sections of "Site 859," Behrmann, Lewis, Musgrave, et al., 1992).

In the upper $1000 \mathrm{cmbsf}$, the $K 1$ axes are scattered in a plane close to horizontal, and although the pattern of the $K 3$ axis is patchy, the mean $K 3$ is vertical. We can interpret the data as the result of a sedimentary fabric.

Below $1000 \mathrm{cmbsf}$, the $K 3$ axes are clustered in an east-west azimuth (mean $\mathrm{D}_{\mathrm{K} 3}=280^{\circ}$ ) and exhibit a progressively shallowing inclination. The mean $K 3$ direction corresponds to the pole of an inclined 
A
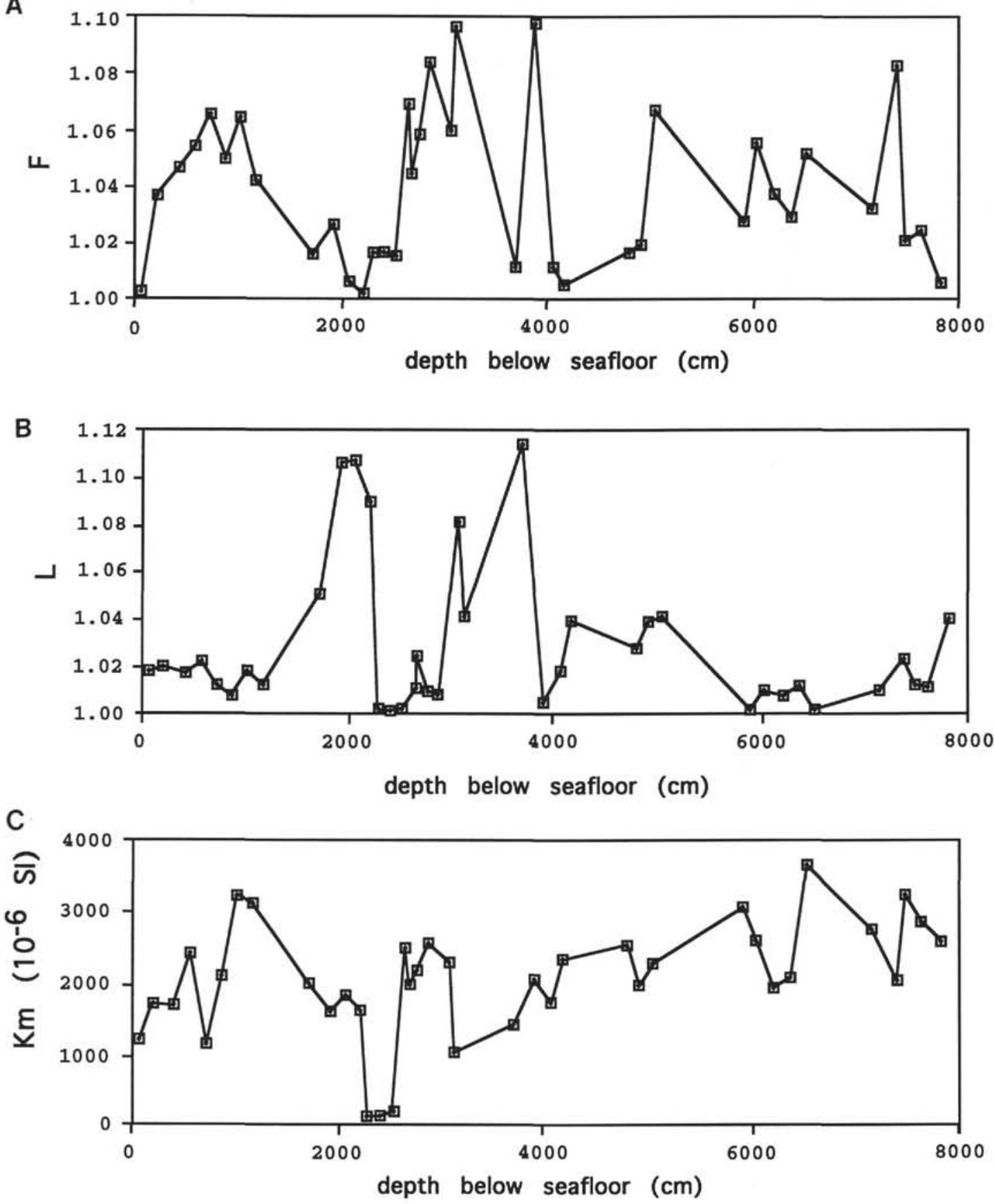

Figure 10. Evolution with depth at Site 861. A. Magnetic foliation parameter, F. B. Magnetic lineation parameter, $L$. C. Bulk susceptibility.

plane in which the $K 1$ axes are scattered. Despite the scattering of the principal axes directions, the results can be interpreted as an east-west maximal shortening and an increasing deformation with depth.

\section{Intensity and Shape of the Magnetic Ellipsoid}

Foliation planes are clearly preponderant in most of the samples from Site 863 . The shape of the susceptibility ellipsoid is predominantly oblate but varies with depth, with samples exhibiting triaxial or slightly prolate ellipsoids (Fig. 14). The high and increasing foliation parameters together with some relatively high-angle lineation confirm the presence of increasing strain from the top to the bottom of the sequence.
As Site 863 is located at the base of the trench slope, at the point where the ridge is being subducted, the magnetic fabric was supposed to reflect a high strain deformation. Primary results from sedimentologic and structural geologic studies made during the leg define two lithostratigraphic units in the first $5000 \mathrm{~cm}$ of sediment:

A thin unit of Quaternary unlithified, undeformed, silty clay to clayey silt $(0-330 \mathrm{cmbsf})$.

A second unit of upper Pliocene sulfide-organic-rich silty clay $(330-4660 \mathrm{cmbsf})$. This unit is strongly deformed, with deformation bands and faults. The distribution and character of faults are heterogenous and complex, and include reverse faults and normal faults, which are dominant and postdate the former. However, samples were not taken where faults are visible in order to reflect a more homogeneous deformation. 

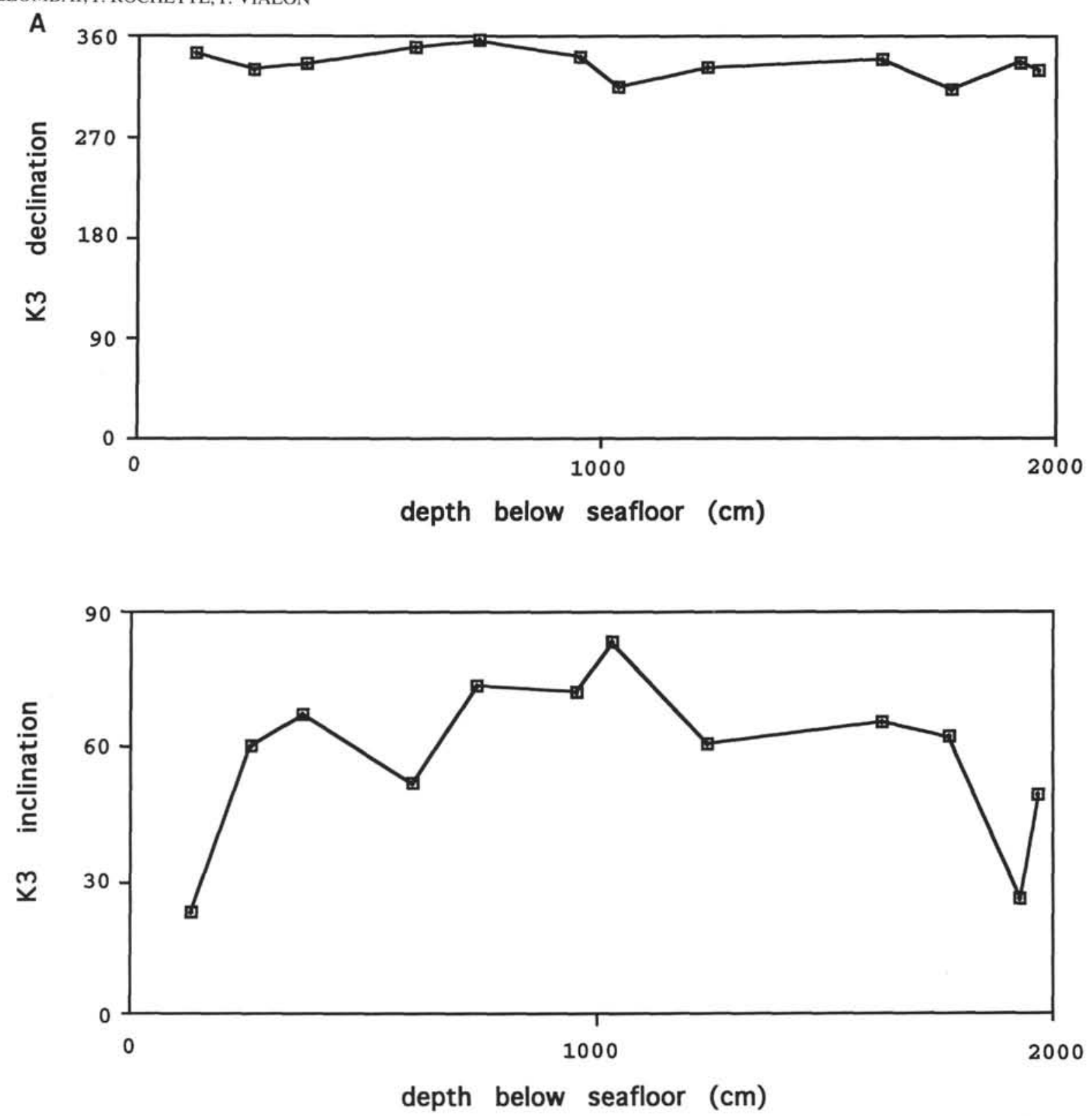

B

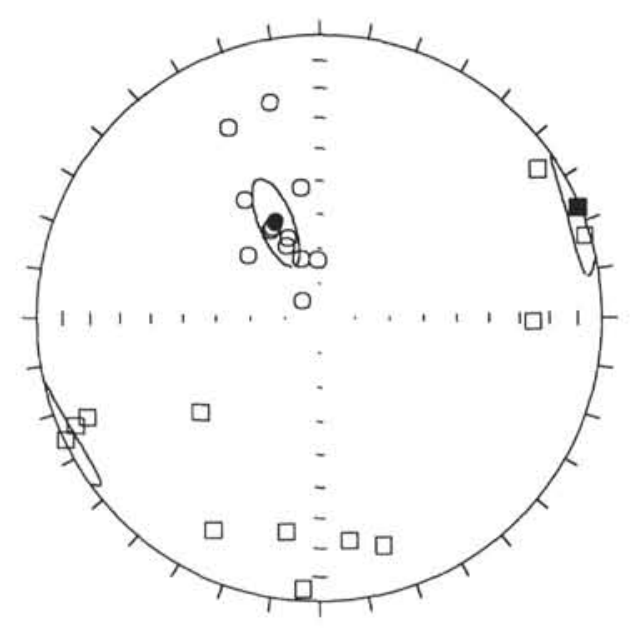

ams 862

Figure 11. A. Variation of $K 3$ declination and inclination with depth at Site 862. B. Stereogram of AMS principal directions at Site 862. Lower hemisphere projection in geographic coordinates (assuming ChRM along north) showing individual $K 3$ (circles) and $K 1$ (squares) specimen directions together with tensorial averaged directions and their ellipse of confidence (Jelinek, 1978). 


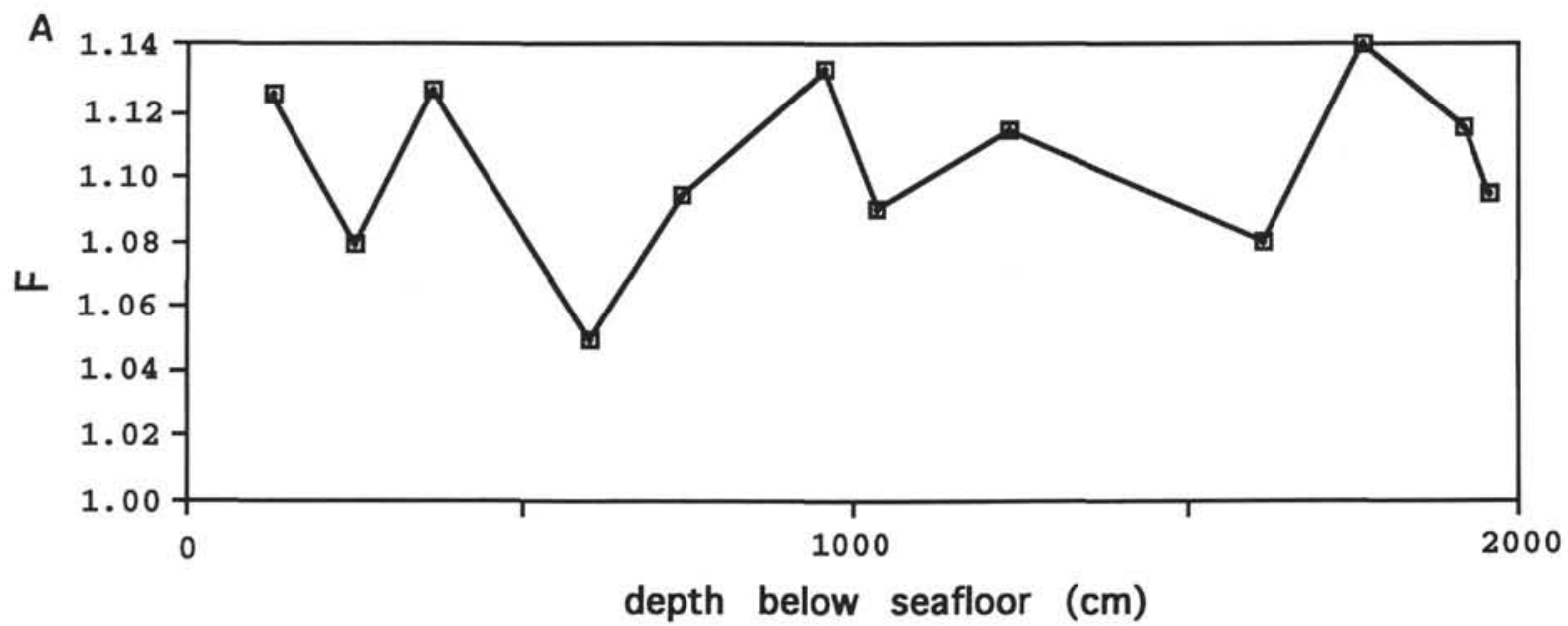

B
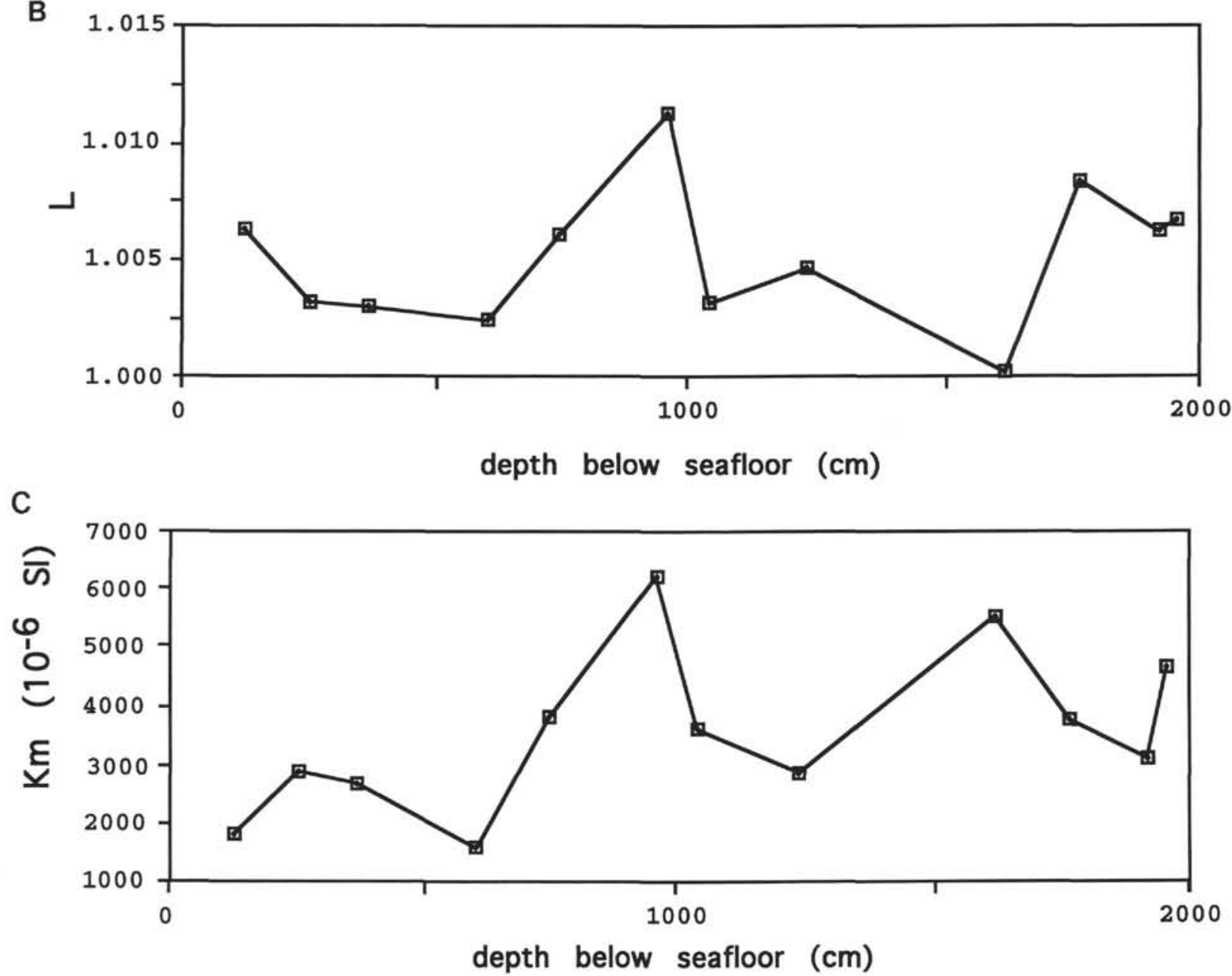

Figure 12. Evolution with depth at Site 862. A. Magnetic foliation parameter, $F$. B. Magnetic lineation parameter, $L$. C. Bulk susceptibility.

The AMS results confirm the presence of a deformed sedimentary sequence below the first $300 \mathrm{~cm}$ of undeformed unit showing a depositional fabric. The direction of maximal shortening inferred from the $K 3$ azimuth is globally vertical at the top of the section (although $K 3$ declinations are scattered), and is reoriented west-northwest-east-southeast below $1000 \mathrm{cmbsf}$. It can be interpreted in this second unit as a maximum shortening direction, which is approximately perpendicular to the ridge and the trench trends, and could be related to thrusting and plate convergence. An alternative explanation for this change in the magnetic fabric could be a variation in the magnetic grain size between the upper and the lower part of the studied section, producing a inverse fabric due to the presence of SD magnetite in the lower part. However, the hysteresis results of Musgrave et al. (this volume) gave a $\mathrm{H}_{c r} / \mathrm{H}_{c}$ ratio of 6.24 at a depth of $23.20 \mathrm{mbsf}$, which corresponds to MD particles (Day et al., 1977).

The remanence data from shipboard measurements show variations in the demagnetized intensity record over the interval from 1400 to $2400 \mathrm{cmbsf}$. The ChRM intensity varies systematically more 

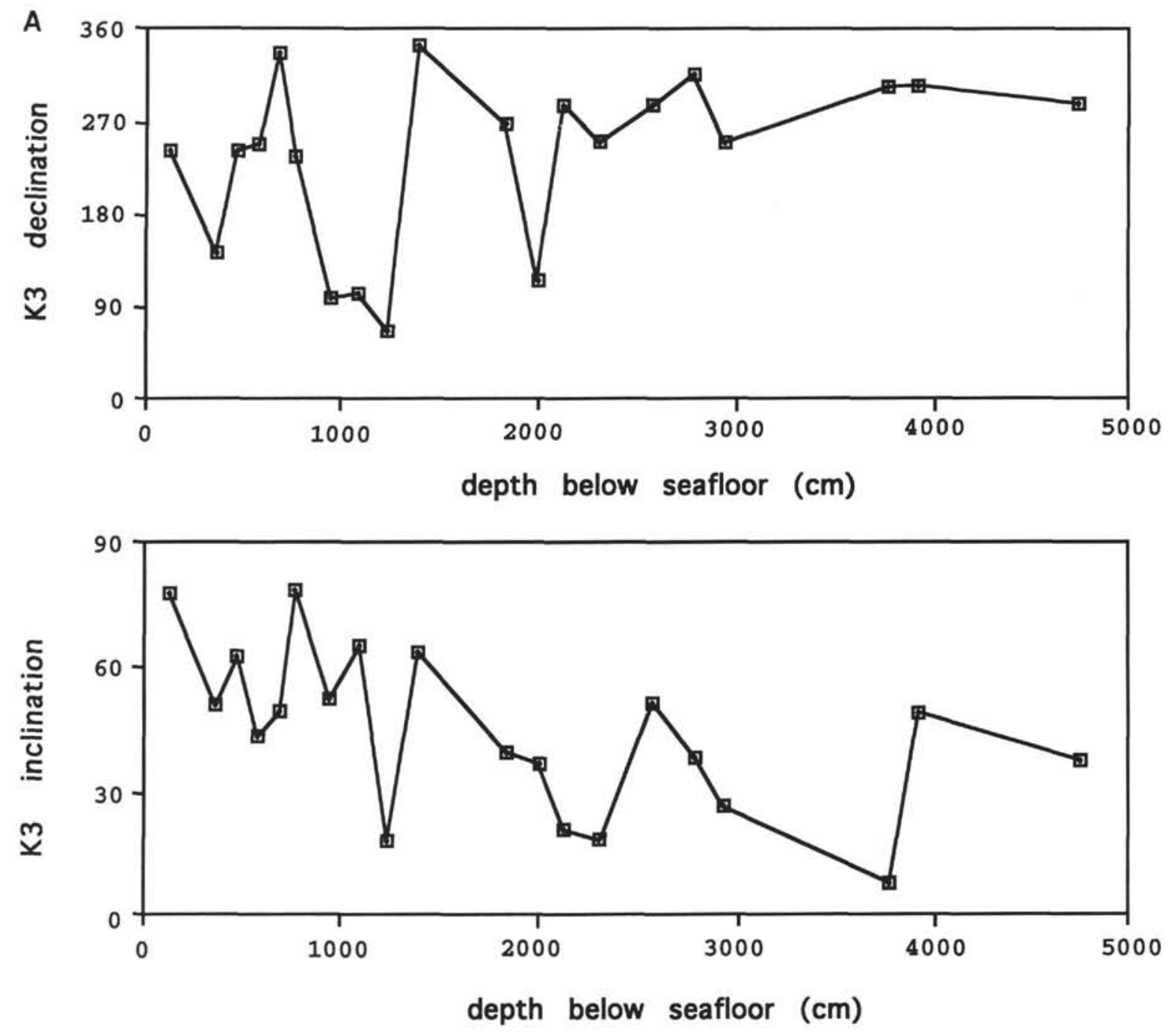

B

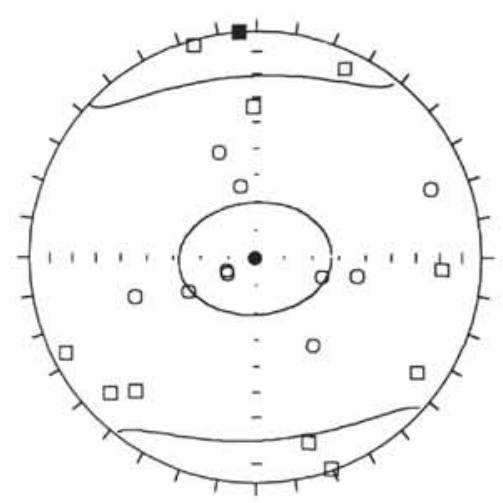

ams 863 top

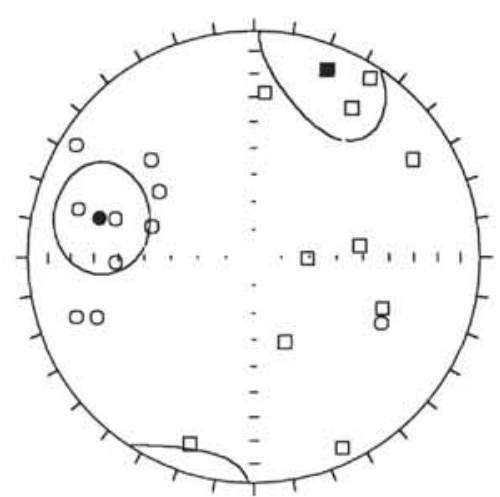

ams 863 bottom

Figure 13. A. Variation of $K 3$ declination and inclination with depth at Site 863. B. Stereograms of AMS principal directions at Site 863 for the top (0-1377 $\mathrm{cmbs}$ ) and bottom parts of the section (1833-4720 cmbsf). Lower hemisphere projection in geographic coordinates (assuming ChRM along north) showing individual $K 3$ (circles) and $K 1$ (squares) specimen directions together with tensorial averaged directions and their ellipse of confidence (Jelinek, 1978). 

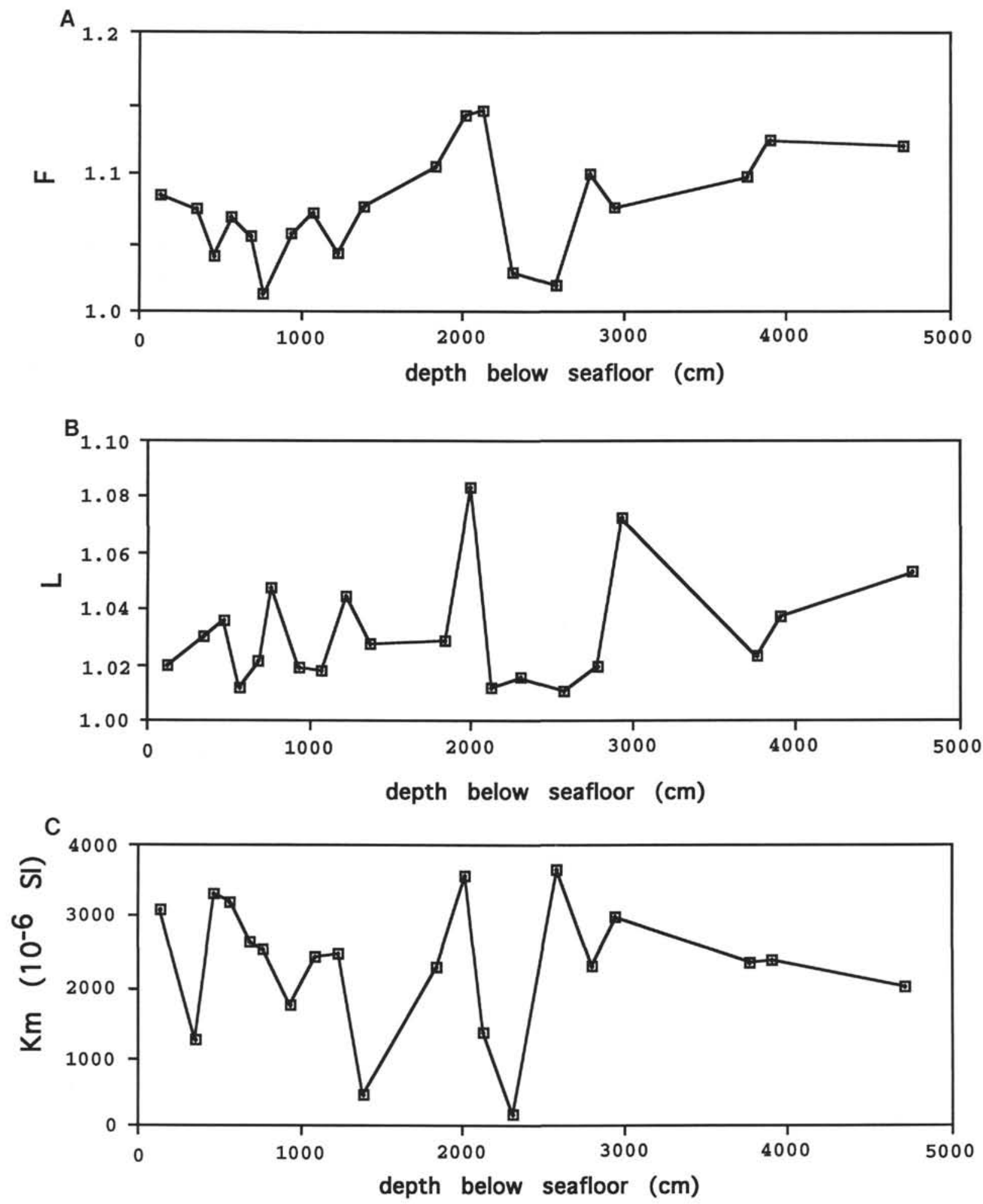

Figure 14. Evolution with depth at Site 863. A. Magnetic foliation parameter, $F$. B. Magnetic lineation parameter, $L$. C. Bulk susceptibility,

than two orders of magnitude over this interval, and present rise and fall, which are repeated in the susceptibility data, and in the proportion of NRM intensity remaining after demagnetization and the Königsberger (Qn) ratio (Behrmann, Lewis, Musgrave, et al., 1992). These variations in intensity and other magnetic parameters over $2400 \mathrm{cmbsf}$ may be related to dissolution of magnetite and the devel- opment of magnetite iron sulfide (pyrrhotite and/or greigite). The presence of greigite is also confirmed by the rock magnetic results (especially the thermal behavior) of Musgrave et al., (this volume). Such authigenic magnetic carrier is not likely to develop with a preferred axis orientation and should not contribute to the change in fabric observed below $1000 \mathrm{cmbsf}$. 


\section{RELATIONSHIP BETWEEN ChRM AND AMS}

Sites 859,860 , and 861 form a downdip transect across the forearc basin and the underlying accretionary wedge, approximately perpendicular to the ridge axis and slightly oblique to the trench axis (Fig. 1B). These sites exhibit low values of ChRM inclination compared with the expected $-65^{\circ}$ geocentric axial dipole inclination $\left(I_{\mathrm{GAD}}\right)$ in the upper part of the studied section $(0-1000,500-1800$, and $0-1200$ cmbsf at Sites 859,860 , and 861 , respectively). Because the magnetic fabric is a typically primary sedimentary fabric in these zones (i.e., planar and horizontal), the NRM data could reflect inclination shallowing related to the preferred orientation of the maximum susceptibility axes of the remanence-carrying grains within the horizontal plane. This preferred orientation, principally resulting from depositional effect in the shallow sediments, is exhibited by the magnetic anisotropy of the magnetic particles (maximum susceptibility axes generally coincide with the long axes of non-spherical particles). The preferred orientation and resulting magnetic anisotropy of the sediment both (different from magnetic anisotropy of the particles) can be estimated by the measurement of AMS.

In order to test this hypothesis of inclination error, we tried to establish a correlation between the degree of anisotropy and inclination anomalies, $D I\left(D I=\mathrm{I}_{\mathrm{GAD}}-\mathrm{I}_{\mathrm{NRM}}\right)$, as successfully done by Jackson et al. (1991) for artificial sediments and Collombat et al. (1993) for natural sediments. We found a correlation between $P$ (AMS) and DI in the upper part at Sites 859 and 861 , although the latter exhibits weak $D I$ values (mean $D I=7.2^{\circ}$ ) (Fig. 15A). However, the AMS is influenced more by larger multidomain rather than by single or pseudosingle domain of magnetic minerals, and also by the matrix minerals. In order to reflect the fabric of the NRM-carrying particles, it is therefore preferable to measure the anisotropy of anhysteretic remanence (AAR) (McCabe et al., 1985; Jackson et al., 1991). The estimation of an anhysteretic anisotropy parameter $(\mathrm{Ha})$, defined by the ratio of horizontal and vertical ARM magnitude, was made using the method of Collombat et al. (1993). We obtained a good correlation between anisotropy parameter $\mathrm{Ha}$ and the inclination anomaly $\mathrm{DI}$, which is arguably the explanation for the occurrence of inclination shallowing in the upper part of the sediment section at Sites 859 and 861 .

Site 860 exhibits very weak values of anisotropy (mean $P=1.025$ between 500 and $1800 \mathrm{cmbsf}$ ), and no correlation between $D I$ and $P($ AMS $)$.

These results confirm the occurrence of inclination errors in sediments and suggest that caution must be exercised in interpreting the NRM inclinations in paleomagnetic studies. In the deformed lower part of the cores $859,860,861$ and 863 , ChRM still appears to have a consistent present day dipole inclination. This strongly support the other evidence for ChRM to be of recent, post-deformational, origin.

\section{DISCUSSION AND CONCLUSION}

This study is concerned with three related tensors (magnetic susceptibility, strain, and stress). Qualitative and semi-quantitative correlation between strain and AMS have been established in several studies (Borradaile, 1988; Lowrie, 1989; Jackson and Tauxe, 1991). The magnetic fabric is controlled by the strain tensor as soon as the tensor is strong enough to overprint and obliterate the primary depositional fabric of the sediment. This situation occurred in most of the drilled sites in the Chile Triple Junction area, below an upper undeformed section that varies in length. It has, therefore, been possible to infer the most likely orientations of the principal strain axes. However, caution must be exercised at sites where only weak deformation is present in interpreting the data in terms of strain directions. The actual strain response (compression or extension) may be combined with the depositional fabric, especially at low strains, and complicates the interpretation.

The relation between stress and strain is less straightforward. The principal axes of stress and strain are supposed to be parallel, but only in the case of homogeneous deformation without rotation, in isotropic bodies.

Part of the deformation at each site should be related to downslope sliding and slumping in these relatively soft sediments. The principal driving force should be gravity, especially in the steep topography of the ridge axis-parallel accretionary wedge. However, the shipboard sampling was selective, and highly deformed zones, where bedding is not preserved, were not sampled. Thus, we can suppose that the strain directions inferred from the magnetic fabric at the Sites 859 , 860 , and 861 are consistent through the transect from the ridge to the trench, in the direction of the plates tectonic convergence.

Below the upper part of the section exhibiting primary sedimentary fabric (vertical $K 3$ axes), $K 3$ axes are reoriented and scattered in an approximately horizontal plane at Sites 859 and 860 . For the latter site, $K 3$ axes are less scattered and exhibit a west-northwest-eastsoutheast azimuth. Site 861 exhibits a primary depositional fabric but some parts of the sections exhibit again a shallowing and striking in a west-northwest azimuth $K 3$ axes. Underlying basement at Site 861 is the South American continental basement, and the sediments have probably been more passively transported. Thus, this site has suffered less deformation, especially in the upper $30 \mathrm{mbsf}$.

The reorientation of the $K 3$ axes with depth for each site along the transect seems to be related to the location of the site with respect to the ridge and the trench (Fig. 1).

In the western edge of the forearc (Site 859), below the first 1000 cmbsf, the horizontal distribution of the $K 3$ axes, the vertical $K 1$ directions, and the somewhat high values of lineations can be interpreted as upward vertical flowing or stretching of the sediment in response to tightening and compression linked to the collision.

Further landward (Site 860), the evolution of the sediment fabric with depth is similar to that at Site 859 , but below the almost undeformed part, the $K 3$ axes are more clustered and horizontal and strike in a west-northwest-east-southeast azimuth. This direction is approximately perpendicular to the trench axis (which is oriented globally north-south) and can be interpreted as the direction of maximum shortening. Moreover, the $K 1$ axes are clustered closer to the vertical and suggest a more intense stretching of the sediment in the vertical direction. The strain at this site can also be related to plate convergence and collision, and the induction of vertical flow is suggested by the vertical linear organization of the material.

At Site 861, located in the forearc on the middle trench slope of the South American continental margin, the studied sequence has been passively transported and is less deformed. The primary depositional fabric is globally well preserved.

At site 862, the Taitao Ridge may have originated by transform fault deformation and "leaky transform" magmatism along the Taitao Fracture Zone. At this site, the geodynamic context is complex and the mechanism responsible for the structure may be related to a tectonic translation of the sediment cover, possibly with rotation, owing to the spreading of the underlying oceanic basement. The AMS results show a well-defined flattening plane with a pole determined by the mean $K 3$ axis, which exhibits a north-northwest azimuth and an approximately $60^{\circ}$ inclination. The results can reflect a sedimentary fabric and a bedding dipping to the south-southeast, into the slope, but are also consistent with the hypothesis of north-northwest-south-southeast compression resulting from overthrust and rotation on the transform fault.

At Site $863, K 3$ axes are scattered about the vertical at the top of the section and are almost horizontal and striking in a west-northwest-east-southeast azimuth below $1000 \mathrm{cmbsf}$. The direction of the principal axis of magnetic susceptibility was interpreted as a global east-west maximum shortening. The direction of tightening or compression inferred from $K 3$ directions in this lower part is globally perpendicular to the ridge and the trench axis and can be interpreted as a consequence of the overthrust.

The magnetic fabric and the strain direction deduced from the principal susceptibility axes are consistent for each site with the regional geodynamic context (i.e., globally east-west convergence of 
A
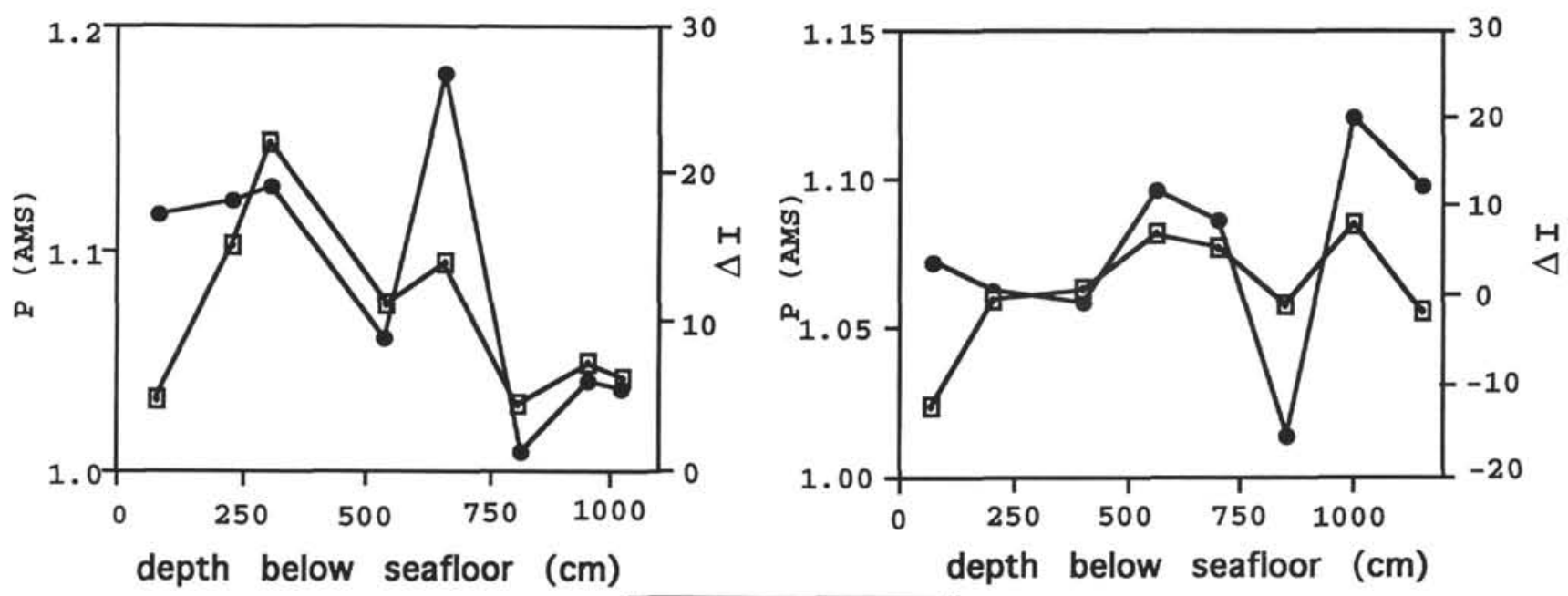

B
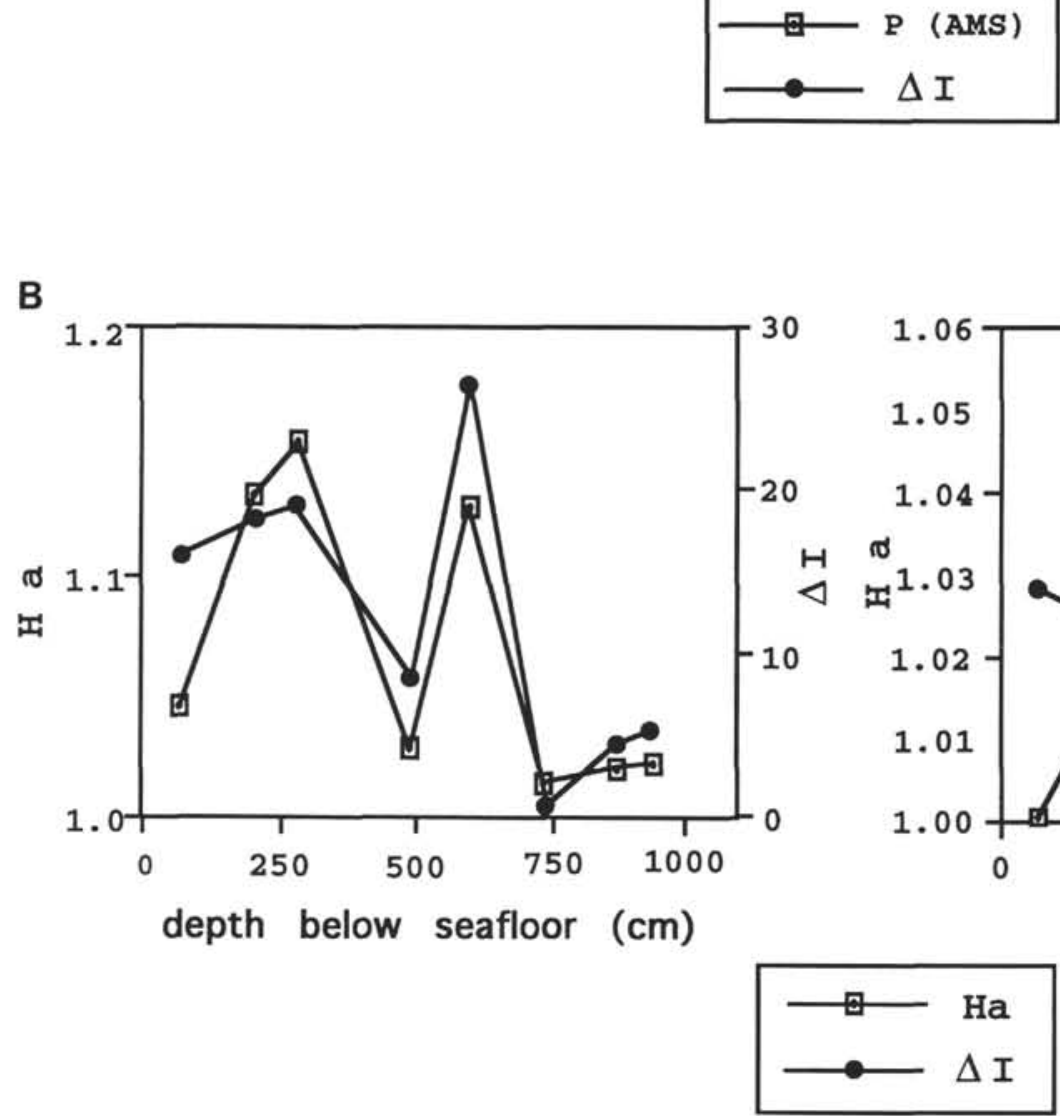

Figure 15. Correlation between (A) inclination error $D I$ and the anisotropy parameter $P(A M S)$ and (B) between $D I$ and the anisotropy parameter $H a$ (anisotropy of $A R M$ ) in the upper part of the drilled section at Sites 859 and 861. 


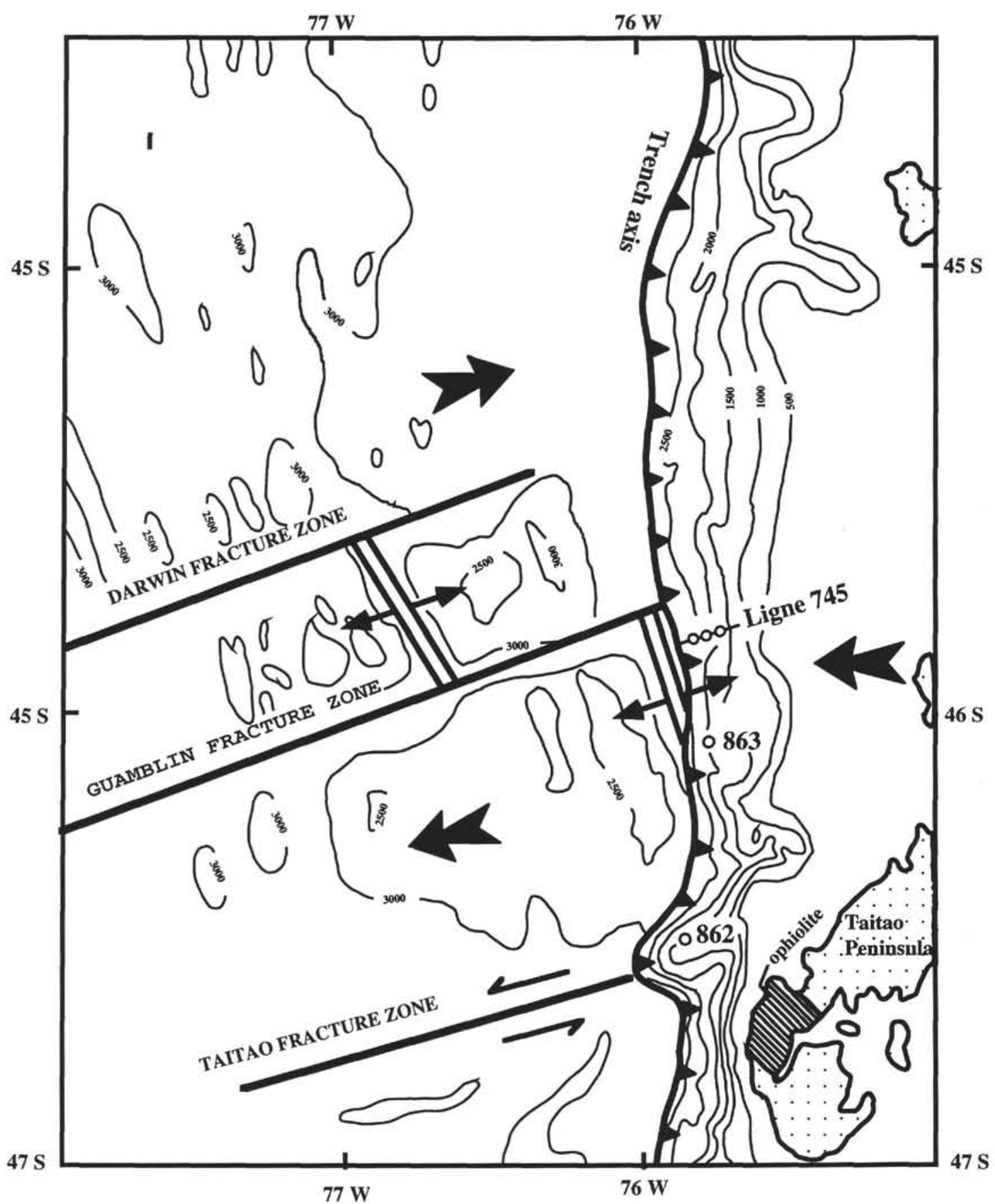

Figure 16. Location of the trench axis, ridge, Taitao Peninsula, and Taitao, Darwin, and Guamblin fracture zones. The spreading direction of the ridge (small arrows) and direction of relative plate motion (big arrows) are also shown. Contour interval in meters.

the plates). Directions of maximum shortening are reported on a synthetic map showing the location of the sites with respect to the trench, the ridge, and the Chile coast (Fig. 16).

\section{REFERENCES*}

Behrmann, J.H., Lewis, S.D., Musgrave, R.J., et al., 1992. Proc. ODP, Init. Repts., 141: College Station, TX (Ocean Drilling Program).

\footnotetext{
Abbreviations for names of organizations and publications in ODP reference lists follow the style given in Chemical Abstracts Service Source Index (published by American Chemical Society).
}

Borradaile, G.J., 1988. Magnetic susceptibility, petrofabrics and strain. Tectonophysics, 156:1-20.

Cande, S.C., Herron, E.M., and Hall, B.R., 1982. The early Cenozoic tectonic history of the Southeast Pacific. Earth Planet. Sci. Lett., 57:63-74.

Cande, S.C., and Leslie, R.B., 1986. Late Cenozoic tectonics of the southern Chile Trench. J. Geophys. Res., 91:471-496.

Cande, S.C. Leslie, R.B., Parra, J.C., and Hobart, M., 1987, Interaction between the Chile Ridge and Chile Trench: geophysical and geothermal evidence. J. Geophys. Res., 92:495-520.

Collombat, H., Rochette, P., and Kent, D.V., 1993. Detection and correction of inclination shallowing in deep sea sediments using the anisotropy of magnetic remanence. Bull. Soc. Geol. Fr., 164:103-111.

Day, R., Fuller, M., and Schmidt, V.A., 1977. Hysteresis properties of titanomagnetites: grain-size and compositional dependence. Phys. Earth Planet. Int., 13:260-266. 
Forsythe, R.D., and Nelson, E., 1985. Geological manifestations of ridge collision: evidence from the golfo de Penas-Taito Basin, southern Chile. Tectonics, 4:477-495.

Hartstra, R.L., 1982. Grain size dependance of initial susceptibility and saturation magnetisation related parameters of four natural magnetites in the PSD-MD range. Geophys. J.R. Astr. Soc., 71:477-495.

Herron, E.M., Cande, S.C., and Hall, B.R., 1981. An active spreading center collides with a subduction zone: a geophysical survey of the Chile margin triple junction. Mem.-Geol. Soc. Am., 154:683-701.

Hrouda, F., 1982. Magnetic anisotropy of rocks and its application in geology and geophysics. Geophys. Surv., 5:37-82.

Jackson, M., Banerjee, S., Marvin, J., Lu, R., and Gruber, W., 1991. Detrital remanence, inclination errors and anhysteretic remanence anisotropy: quantitative model and experimental results. Geophys. J. Int., 104:95-103.

Jackson, M., and Tauxe, L., 1991. Anisotropy of magnetic susceptibility and remanence: developments in the characterization of tectonic, sedimentary and igneous fabric. Rev. Geophys., (Suppl.), 29:371-376.

Jelinek, V., 1978. Statistical processing of anisotropy of magnetics susceptibility measured on group of specimen. Studia Geoph. et Geod., 22:50-62.

Lowrie, W., 1989. Magnetic analysis of rock fabric. In James, D.E. (Ed.), The Encyclopedia of Solid Earth Geophysics: New York (Van Nostrand Reinhold), 698-706.
McCabe, C., Jackson, M., and Ellwood, B.B., 1985. Magnetic anisotropy in the Trenton Limestone: results of a new technique, anisotropy of anhysteretic susceptibility. Geophys. Res. Lett., 12:333-336.

Pilger, R.H., Jr., 1978. A method for finite plate reconstructions, with applications to Pacific-Nazca plate evolution. Geophys. Res. Lett., 5:469-472.

Rochette, P., 1987. Magnetic susceptibility of the rock matrix related to magnetic fabric studies. J. Struct. Geol., 9:1015-1020.

Rochette, P., Jackson, M., and Aubourg, C., 1992. Rock magnetism and the interpretation of anisotropy of magnetic susceptibility. Rev. Geophys., 30:209-226.

Shipboard Scientific Party, 1992. Proc. ODP, Init. repts., 141: College Station, TX (Ocean Drilling Program).

Tarling D.H., 1983. Palaeomagnetism, principles and applications in geology, geophysics and archaeology. Chapman and Hall Ltd, London, New York, $379 \mathrm{p}$.

Date of initial receipt: 9 August 1993

Date of acceptance: 15 August 1994

Ms 141SR-012 